\title{
DIREITO AO CONFRONTO \\ E DECLARAÇÕES DO CORRÉU
}

\author{
Dissertação de Mestrado \\ Orientador: Professor Associado Dr. Maurício Zanoide de Moraes
}

UNIVERSIDADE DE SÃO PAULO

FACULDADE DE DIREITO

São Paulo - SP

2018 



\section{DIREITO AO CONFRONTO}

\section{E DECLARAÇÕES DO CORRÉU}

Dissertação apresentada à Banca Examinadora do Programa de Pós-Graduação em Direito, da Faculdade de Direito da Universidade de São Paulo, como requisito parcial para obtenção do título de Mestre em Direito, na área de concentração Direito Processual, sob a orientação da Prof. Associado Dr. Maurício Zanoide de Moraes.

UNIVERSIDADE DE SÃO PAULO

FACULDADE DE DIREITO

São Paulo - SP

Janeiro/2018 


\section{Catalogação-na-Publicação Serviço de Biblioteca e Documentação \\ Faculdade de Direito da Universidade de São Paulo}

Bragagnollo, Daniel Paulo Fontana
Direito ao Confronto e Declarações do Corréu / Daniel Paulo Fontana

Bragagnollo ; orientador Maurício Zanoide de Moraes -- São Paulo, 2018.

$414 \mathrm{p}$.

Dissertação (Mestrado - Programa de Pós-Graduação em Direito

Processual) - Faculdade de Direito, Universidade de São Paulo, 2018.

1. Direito Processual Penal. 2. Direito ao Confronto. 3. Interrogatório. 4. Prova Testemunhal. I. Moraes, Maurício Zanoide de, orient. II. Título. 
Nome: BRAGAGNOLLO, Daniel Paulo Fontana; FONTANA BRAGAGNOLLO, Daniel Paulo; BRAGAGNOLLO, Daniel

Título: Direito ao Confronto e Declarações do Corréu

Dissertação apresentada à Faculdade de Direito da Universidade de São Paulo como requisito parcial para obtenção do título de Mestre em Direito.

Aprovado em:

Banca Examinadora:

Presidente (Orientador): Prof. Dr. Maurício Zanoide de Moraes

Julgamento: Assinatura:

Prof. Dr. Instituição:

Julgamento: Assinatura:

Prof. Dr. Instituição:

Julgamento: Assinatura:

Prof. Dr. Instituição: Julgamento: Assinatura: 

Dedico este trabalho aos meus pais, Paulo e Sandra

"Por onde você for eu sigo com o meu pensamento sempre onde estiver" (Joel Marques) 



\section{AGRADECIMENTOS}

Àqueles de quem serei sempre aluno e representam para mim exemplos e referências para minha formação acadêmica: Maurício Zanoide de Moraes, Gustavo Badaró e Marcos Zilli.

A Maurício Zanoide de Moraes, também pela confiança como seu orientando;

A Gustavo Badaró e Marcos Zilli, também por uma das mais enriquecedoras aulas que me proporcionaram por ocasião da banca de qualificação.

A John D. Jackson e a Stefano Maffei, pelo acolhimento em meu período de pesquisas, por toda a atenção e pelos enriquecedores e abertos diálogos comparados.

Ao Departamento Jurídico XI de Agosto, ontem, hoje e sempre, pelo que significa em minha vida e pelo que representa em minhas escolhas.

Às bancas de advocacia nas quais tive oportunidade de aprender, me formar enquanto profissional e solidificar meus ideais — na pessoa de meu mentor, Fábio Tofic Simantob.

Aos grandes amigos que o mundo jurídico e nossa Sanfran me deram, que fazem a vida valer a pena. Sabem quem são, pois em todo o curso deste trabalho não faltaram reafirmações das verdadeiras amizadas. Valeu, meus nakamas!

A Matheus Ereno Antoniol, meu irmão e sócio, por toda a parceria pessoal e profissional;

A Fernando Gardinali Caetano Dias, pela parceria fiel ao longo do mestrado.

À "Família Agregada", liderada por Celso e Solange Giovannoni, cuja importância em minha vida sempre se renova e só se intensifica: Dante Crotti, Tatiane Fiori, Tomaz Gaido e as irmãs e minhas irmãs, Cristiane e Juliana Giovannoni. 
Aos meus familiares, pelo apoio e, provavelmente acima de tudo, pela compreensão por minhas ausências decorrentes dos esforços para a conclusão deste trabalho - na pessoa da Vó Cristina, dos meus padrinhos, Tio Pedro e Tia Soraya, e da minha tia Mariza (sempre, Iza - seus entusiastas votos servem de motivação impagável para mim.

Ao meu irmão João Paulo, à minha cunhada Lidia e, é claro, ao meu sobrinho Julian, pela renovação, pelo ressignificado da vida.

A meus avós, Laurindo e Antonieta, meus segundos pais, que sempre demonstram um apoio e um amor por mim que não é desse mundo.

E, por último, sim, o mais importante: a meus pais, Paulo e Sandra. Obrigado por tudo. Esse trabalho é devido muito mais a vocês do que a mim mesmo.

Parte em São Paulo, parte em Cosmópolis, no calor de 2017/2018. 
"desde o tempo em que por meio de um só homem o pecado entrou no mundo e, pelo pecado, a morte, e assim a morte passou a todos os homens, porque todos pecaram (Rm 5:12), toda a massa de perdição tornou-se possessão do corruptor. Assim, ninguém, absolutamente ninguém desde então, se isentou ou se isenta ou se isentará do pecado, a não ser pela graça do Redentor".

(Santo Agostinho. A Graça de Cristo e o Pecado Original. Livro II “O Pecado Original”, Capítulo XXIX, § 34). 



\section{RESUMO}

BRAGAGNOLlO, Daniel Paulo Fontana. Direito ao confronto e declarações do corréu. Dissertação (Mestrado) - Faculdade de Direito, Universidade de São Paulo, São Paulo, 2018, $414 \mathrm{p}$.

O tema da presente dissertação é o direito ao confronto e as declarações do corréu. Seus objetivos principais são analisar a incidência do direito ao confronto na tomada de declarações do corréu, e as consequências jurídicas advindas das violações a este direito fundamental. Para enfrentamento, inicia-se com a definição do direito ao confronto como direito fundamental vigente no Brasil pela adesão à Convenção Americana de Direitos Humanos e ao Pacto Internacional de Direitos Civis e Políticos, bem como estabelecendo o paradigma confrontativo, assim entendido como modelo teórico para análise de sua introdução e implementação no ordenamento jurídico. A seguir, definem-se as hipóteses de declarações do corréu. Estabelecidas essas premissas, adota-se o método comparado para investigar o tratamento do direito ao confronto e das declarações do corréu em outras jurisdições estrangeiras e internacionais, como referência à análise do tema deste trabalho no ordenamento nacional. Por fim, o tema-problema é desafiado à luz do direito processual penal brasileiro, ocasião em que se verificará a aplicação do paradigma contrativo previsto nas normas abstratas, posicionando-nos sobre as consequências jurídicas da violação ao direito ao confronto e aduzindo se o Brasil atende ao compromisso internacional de implementar e proteger este direito fundamental.

Palavras-chave: Direito ao Confronto. Declarações do Corréu. Testemunhas Contrárias. Corréu Ausente. Paradigma Confrontativo. 



\begin{abstract}
BRAGAGNOLLO, Daniel Paulo Fontana. Right to confrontation and codefendant's statements. Dissertation (Master) - Law School, University of São Paulo, São Paulo, 2018, $414 \mathrm{p}$.

This dissertation investigates the right to confrontation and the codefendant's statements. Its main goals are to analyze the incidence of the right to confrontation in cases which one codefendant implicates another defendant, and the upcoming consequences from wrongful departures from this fundamental right. First step, we will define the right to confrontation as a fundamental right in force in Brazil by virtue of both American Convention on Human Rights and International Covenant on Civil and Political Rights, and we will establish the confrontational paradigm, a theoretical model conceived for analysis of its introduction and protection in a national legal framework. Next, the circumstances of obtaining one codefendant's statements will be defined. Once these premises have been established, a comparative approach will be used to study matters of the right to confrontation and the codefendant's statements in other foreign and international jurisdictions, as a reference to the analysis of these matters in the Brazilian legal framework. Finally, confrontation and codefendant's statements will be challenged in the light of Brazilian Criminal Procedural Law, at which point the confrontational paradigm ruled in the abstract statutes will be verified. We will also present our view about the consequences from wrongful departures and stating whether Brazil meets its international commitment to implementation and protection of the right to confrontation.
\end{abstract}

Keywords: Right to Confrontation. Codefendant's Statements. Witnesses Against the Accused. Absent Codefendant. Confrontational Paradigm. 



\section{LISTA DE ABREVIATURAS E SIGLAS}

$\mathrm{AC}$

All ER

$\mathrm{CADH}$

Cass. crim.

CDHNU

CEA

$\mathrm{CEDH}$

$\mathrm{CF}$

$\mathrm{CIDH}$

CJA

ComIDH

Cort. Cos.

$\mathrm{CP}$

CPC

CP-I

CPP

CPP-I

Cr App R

Crim LR

DUDH

EC

ECHR

ERTPI

EUA

EWCA Crim

FRE

IACHR

JP

OEA
Appeal Cases, Official Law Reports (Inglaterra)

All England Law Reports

Convenção Americana sobre Direitos Humanos

Corte di Cassazione, Sezioni Criminale (Itália)

Comitê de Direitos Humanos das Nações Unidas

Criminal Evidence Act 1898 (Inglaterra)

Convenção Europeia de Direitos Humanos

Constituição Federal (Brasil)

Corte Interamericana de Direitos Humanos

Criminal Justice Act 2003 (Inglaterra)

Comissão Interamericana de Direitos Humanos

Corte Costituzionale (Itália)

Código Penal (Brasil)

Código de Processo Civil (Brasil)

Codice Penale (Itália)

Código de Processo Penal (Brasil)

Codice di Procedura Penale (Itália)

Criminal Appeal Reports (Inglaterra)

Criminal Law Review (Reports) (Inglaterra)

Declaração Universal de Direitos Humanos

Emenda Constitucional (Brasil)

European Court of Human Rights Reports

Estatuto de Roma do Tribunal Penal Internacional

Estados Unidos da América

England and Wales Court of Appeal, Criminal Division

Federal Rules of Evidence (EUA)

Inter-American Commission on Human Rights

Justice of the Peace Reports (Inglaterra)

Organização dos Estados Americanos 
ONU

PACE

PIDCP

QB

STF

STJ

TEDH

TJSC

TJSP

TPI

U.S.

UKHL

UNHRC

WLR

YJCEA
Organização das Nações Unidas

Police and Criminal Evidence Act 1984 (Inglaterra)

Pacto Internacional sobre Direitos Civis e Políticos

Queen's Bench, Official Law Reports (Inglaterra)

Supremo Tribunal Federal (Brasil)

Superior Tribunal de Justiça (Brasil)

Tribunal Europeu de Direitos Humanos

Tribunal de Justiça do Estado de Santa Catarina

Tribunal de Justiça do Estado de São Paulo

Tribunal Penal Internacional

United States Reports

United Kingdom House of Lords

United Nations Human Rights Committee

Weekly Law Reports (Inglaterra)

Youth Justice and Criminal Evidence Act 1999 (Inglaterra) 


\section{SUMÁRIO}

1 INTRODUÇÃO.......................................................................................................21

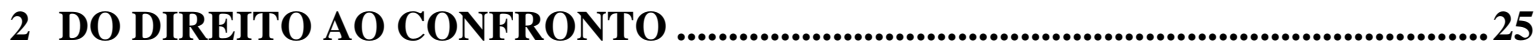

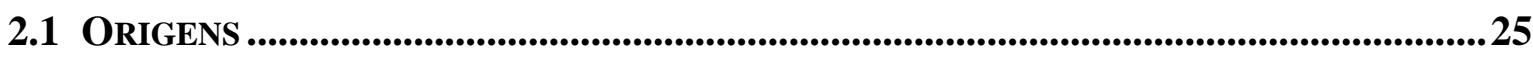

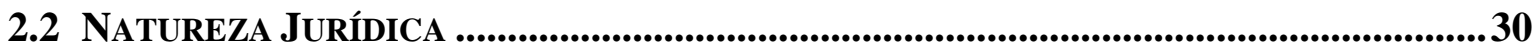

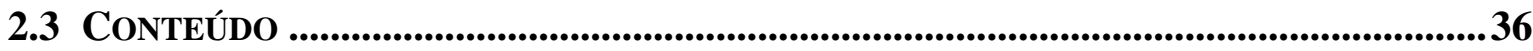

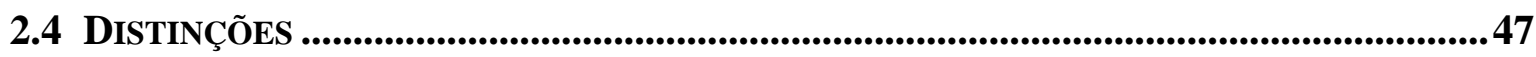

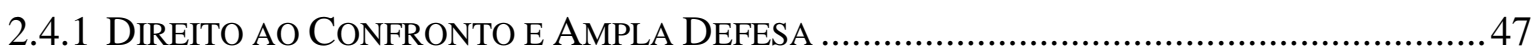

2.4.1.1 Direito ao Confronto e Plenitude de Defesa no Tribunal do Júri..........................56

2.4.2 DiREITO AO CONFRONTO E CONTRADITÓRIO..............................................................59

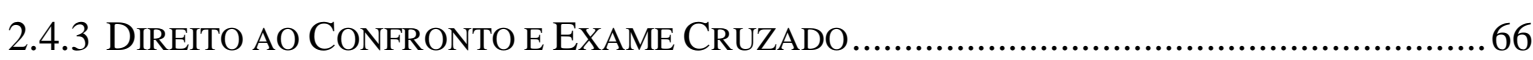

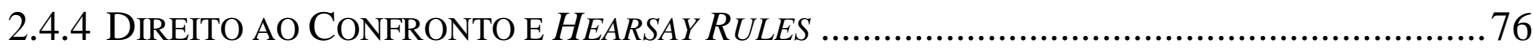

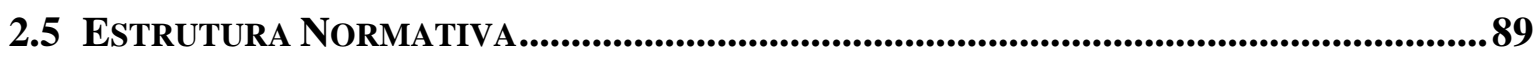

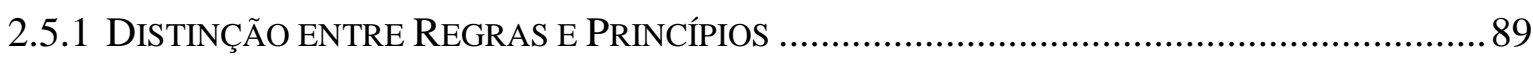

2.5.2 Direito Ao CONFronto COMO NORMA-Princípio E ESTABELECIMENTO DA BASE TEÓRICA PARA SUA RESTRIÇÃO - A REgRA DA PROPORCIONALIDADE ......................... 92

3 DAS DECLARAÇÕES DO CORRÉU ..................................................................101

3.1 HIPÓTESES JURÍDICAS DE OCORRÊNCIA ...............................................................103

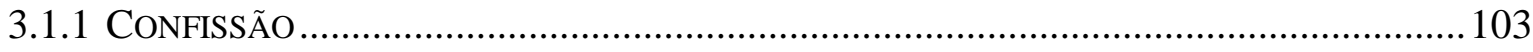

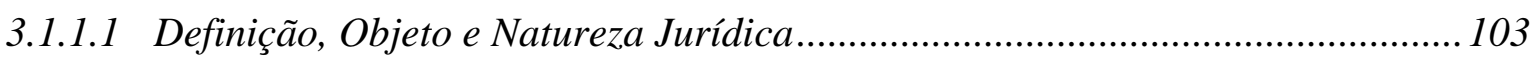

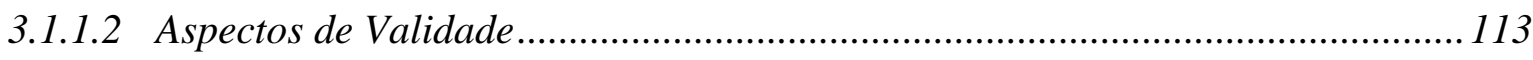

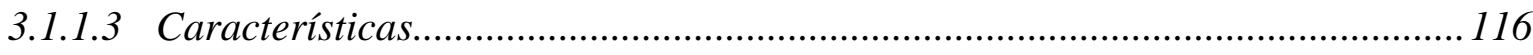

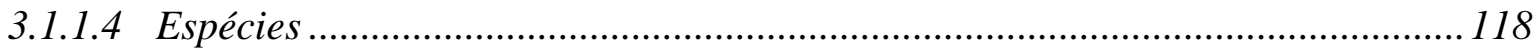

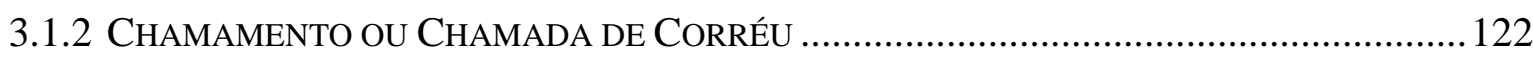

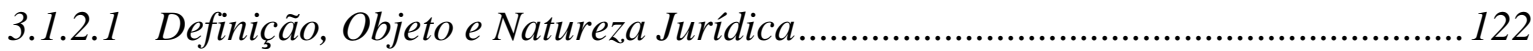

3.1.2.1.1 Chamada de Corréu e Confissão: Intersecção Operativa ...................................125

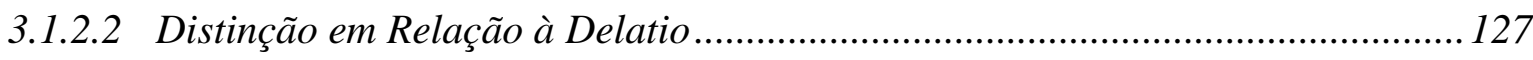

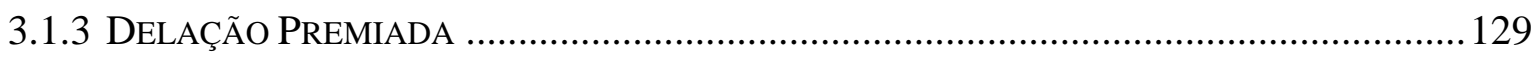

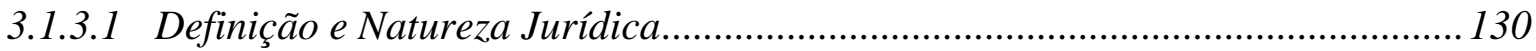

3.1.3.2 Sucessão das Leis sobre Delação Premiada no Tempo ....................................... 133

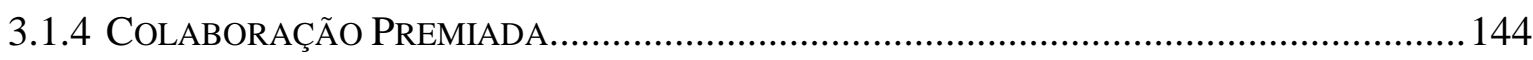

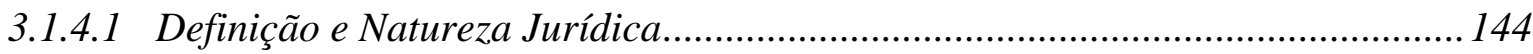

3.1.4.2 Caracteres do Acordo e Hipótese de Incidência .................................................. 152

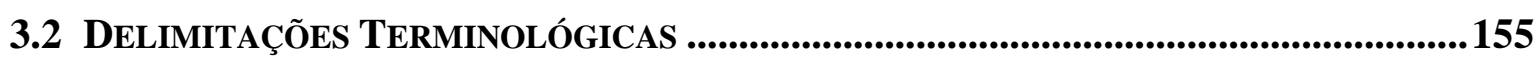

3.2.1 DeClaraÇÕES do CorRÉU COMO ElEMENTOS DE Prova ......................................... 156

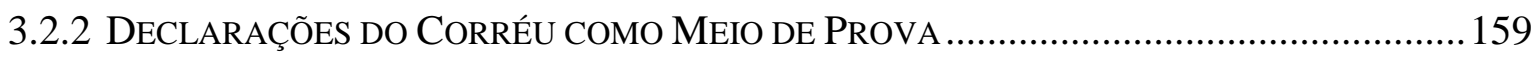


4 DIREITO AO CONFRONTO E DECLARAÇÕES DO CORRÉU EM PERSPECTIVA INTERNACIONAL ..................................................................163

4.1 ESTADOS UNIDOS DA AMÉRICA ..................................................................................164

4.1.1 ConteÚdo do Direito ao Confronto na SuPREMA Corte ...................................165

4.1.1.1 Primórdios do Right to Confrontation na Suprema Corte ..................................165

4.1.1.2 Ohio v. Roberts e a Constitucionalização das Regras sobre Hearsay .................170

4.1.1.3 O Atual Leading Case do Conteúdo do Direito ao Confronto: Crawford v. Washington ............................................................................................... 173

4.1.1.4 Desenvolvimentos do Conceito de Declarações Testemunhais ...........................176

4.1.2 RIGHT TO CONFRONTATION E DECLARAÇÕES DO CORRÉU............................................180

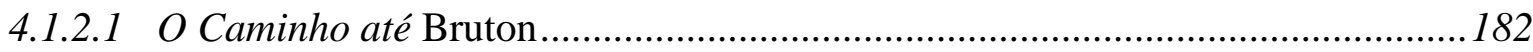

4.1.2.2 O Caso Bruton v. United States................................................................... 184

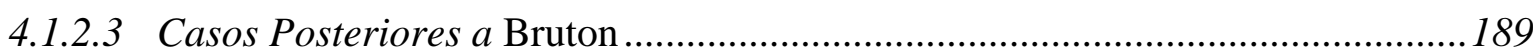

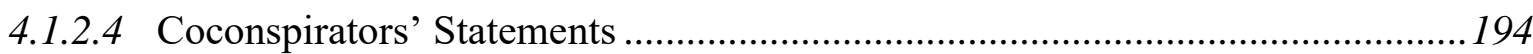

4.1.2.5 Bruton Rule $e$ Coconspirators' Statements ao Advento de Crawford: Algumas Projeções …….....................................................................................199

4.2 INGLATERRA E PaÍS DE GALES .................................................................................201

4.2.1 O PARADIGMA CONFRONTATIVO INGLÊS ............................................................202

4.2.2 Testemunha Ausente e DeClarações do CoRréu Na JuRISDiÇão INGLESA .......211

4.3 REPÚBLICA ITALIANA ............................................................................................220

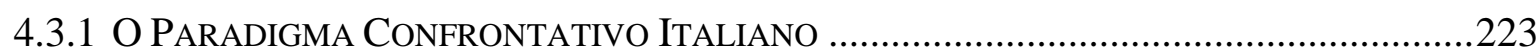

4.3.2 Testemunha Ausente E DeClarações do CoRréu na JuRisDição Italiana......227

4.4 TRIBUnal Europeu de Direitos Humanos ..........................................................231

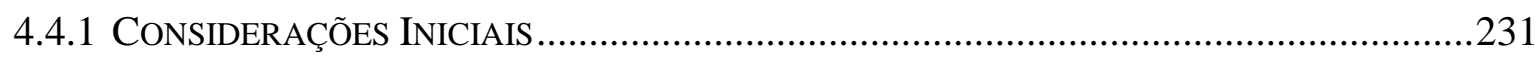

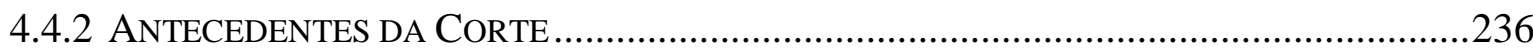

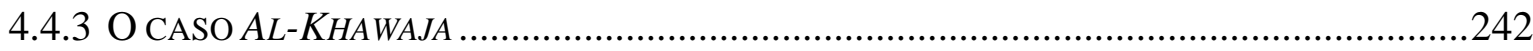

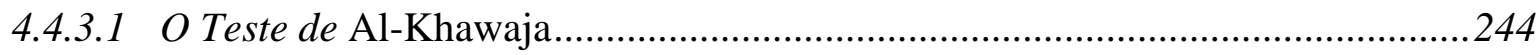

4.4.3.2 Algumas Considerações sobre o Julgamento de Al-Khawaja................................247

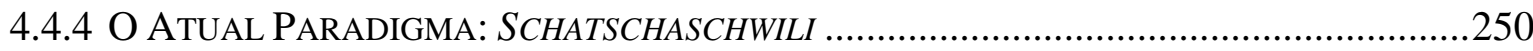

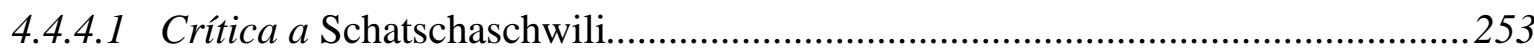

4.5 Comitê de DiReitos Humanos das NaÇões Unidas ..............................................255

4.6 Corte InTERAMERICANa DE Direitos Humanos .....................................................264

5 DIREITO AO CONFRONTO E DECLARAÇÕES DO CORRÉU NO DIREITO PROCESSUAL PENAL BRASILEIRO ...................................................................273

5.1 O Paradigma Confrontativo no Brasil E sua Aplicação Frente às

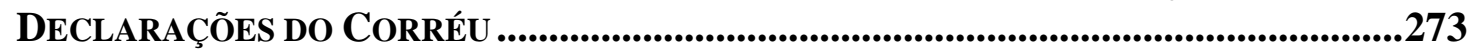

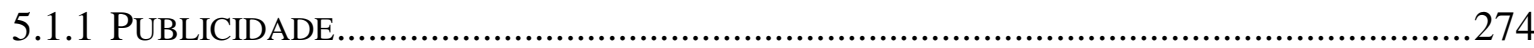

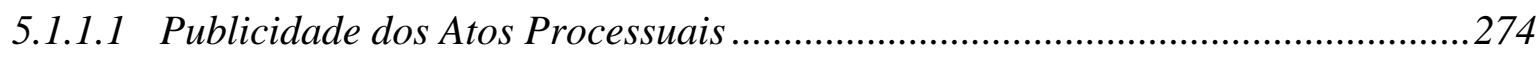

5.1.1.2 Acesso aos Resultados da Investigação Preliminar ............................................279 


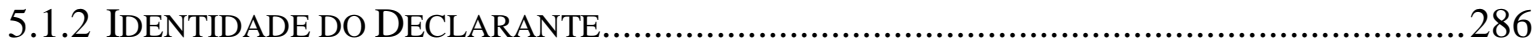

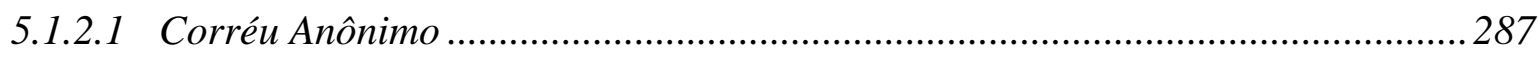

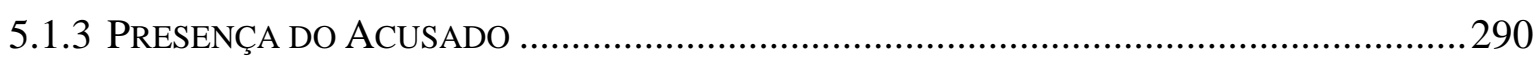

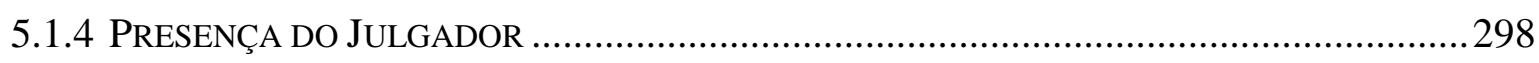

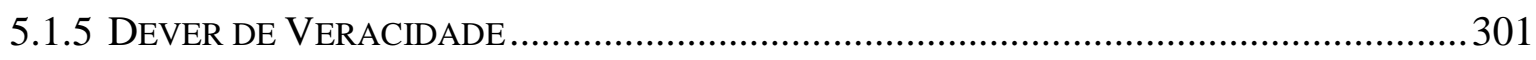

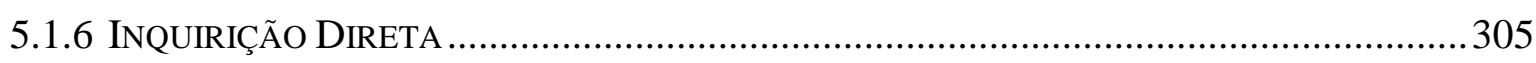

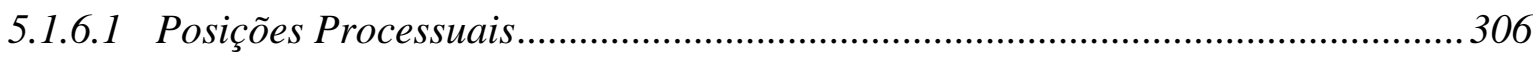

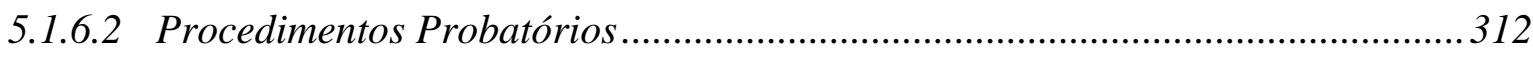

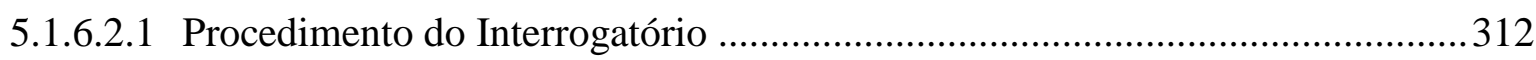

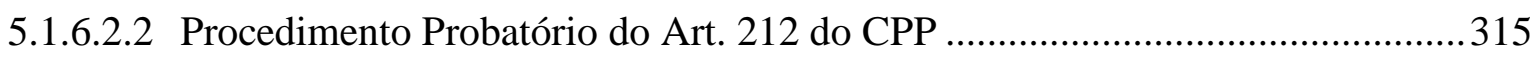

5.2 Direito ao Confronto e SUA COLISÃo CoM o Direito Ao SilênCIO .................318

5.3 Consequência Jurídica da AusênCia de Confronto na Tomada de DECLARAÇÕES DO CORRÉU ................................................................................327

5.3.1 DelimitaÇÃo das DeClarações Confrontadas E Das DeClarações NÃo

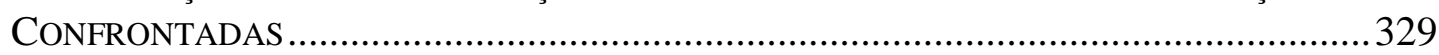

5.3.1.1 (Segue): Corréu Ausente e Exercício do Direito ao Silêncio ................................. 332

5.3.1.2 (Segue): Corréu Ausente e Renúncia ao Direito ao Confronto............................. 337

5.3.2 EnFRENTAMENTO dO STATE OF AFFAIRS: PROIBIÇÃo DE VALORAÇÃo DAS

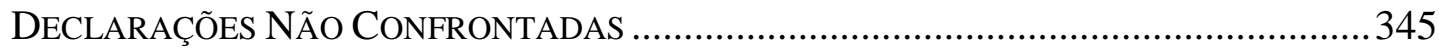

5.3.2.1 (Segue): Declarações Não Confrontadas no Tribunal do Júri .............................. 362

5.3.3 Direito aO CONFronto nO Sistema Processual Penal Brasileiro: ForMALMENTE ASSEGURAdO, MATERIAL E SisteMICAMENTE NEGADO ....................364

6 CONCLUSÃ

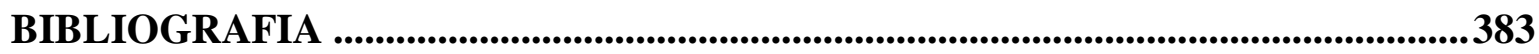

LISTA DAS FONTES JURISPRUDENCIAIS ...................................................... 407 


\section{$1 \quad$ INTRODUĊ̃̃O}

O tema-problema da presente dissertação é direito ao confronto e declarações do corréu. Como recorte central, estudar-se-á a incidência do direito ao confronto no momento da produção das declarações incriminadoras de um corréu perante a autoridade judicial.

O objeto de pesquisa, sem dúvida, está imerso em um conglomerado de problemáticas. Esse conjunto serve a justificar a sua pertinência e a sua atualidade, demonstrando ser o tema-problema eleito campo fértil para o desenvolvimento de pesquisa acadêmica.

A primeira problemática a se aglutinar ao tema é a inexistência de norma expressa, quer no documento constitucional, quer na legislação ordinária, a prover um "direito ao confronto" à pessoa criminalmente acusada. $\mathrm{O}$ compromisso brasileiro em assegurar o direito ao confronto a todos os cidadãos decorre da assinatura de tratados internacionais de direitos humanos. Isso, por si só, na nossa cultura jurídica, evidencia dificuldades que refletem diretamente no modo como esse direito deve ser tratado, debatido e protegido. Nesse sentido, e especialmente no âmbito da justiça criminal, o direito ao confronto será analisado para além de aspectos dogmáticos, apurando-se a postura estatal em dar vazão aos direitos humanos aos quais se comprometeu a assegurar aos cidadãos.

A segunda problemática repousa sobre a inserção do direito ao confronto no campo probatório penal, campo este notadamente conhecido pela sua alta complexidade. Não obstante isso, é consabida a importância nodal da "prova penal" no processo, e sua relação com o sempre erigido conflito entre a eficácia da persecução penal e a proteção dos direitos fundamentais da pessoa criminalmente acusada. Assim sendo, e em grosso modo, o direito ao confronto insere-se como direito eleito pela comunidade internacional a reger a forma como o saber testemunhal incriminador deverá ser apresentado ao julgador de mérito.

Terceira problemática, o apelo representado pelas declarações do corréu. Não é exagero afirmar que muitas investigações - e também acusações formais - têm começo, meio e fim com as declarações do corréu. Desde os interrogatórios policiais do preso em flagrante, realizados nos plantões da madrugada, em Distritos Policiais localizados na periferia dos grandes centros urbanos, até os termos de colaboração premiada que implicam políticos e grandes empresários — as declarações do corréu serão sempre declarações de um “criminoso" que implicam pessoas desde logo também consideradas "criminosas". Os 
reflexos negativos à posição do incriminado aumentam a necessidade de mecanismos de reação e de contrabalanceamentos oferecidos pelo sistema processual. Nesse sentido, o direito ao confronto, enquanto primado da apresentação do saber testemunhal ao julgador de mérito, sobreleva-se em importância.

Quarta e última problemática, o direito ao confronto, quando incindível nas declarações do corréu, é antagonista de outros interesses de mesma hierarquia. Como devem se acomodar o interesse público à efetiva persecução penal, o direito à integridade das fontes pessoais de prova e - de especial interesse - o direito ao silêncio do corréu, frente ao antagônico direito ao confronto, é dúvida que demanda investigação acadêmica.

Essas problemáticas, em conjunto, justificam o trabalho a ser desenvolvido. Mas não apenas isso. Esse campo de dúvidas a serem aqui investigadas tem o condão de incitar ao debate, de promover inquietações e de contribuir para algo que se tem por premissa crítica: o urgente resgate da "justiça criminal" no Estado Democrático de Direito brasileiro, com a elaboração de um novo Código de Processo Penal (CPP) em genuína conformidade com a Carta Cidadã e com os compromissos assumidos perante a comunidade internacional de tutelar direitos humanos.

Nesse desiderato, empreenderemos pesquisa acadêmica cujo centro expositivo será composto por quatro Capítulos.

O Capítulo 2 deste trabalho será dedicado ao estudo do direito ao confronto. Traçar suas origens e seus fundamentos juspolítico e ideológico; sua natureza jurídica; seu conteúdo; e a forma de sua incorporação ao direito brasileiro são ferramentas essenciais ao curso da pesquisa. Para um aprofundamento, o direito ao confronto também será distinguido de outros institutos jurídicos processuais penais de grande importância, com os quais o direito ao confronto forma relevantes relações de complementariedade e coexistência, conquanto com eles não se confunda.

No Capítulo 3, a ocupação será as declarações do corréu. Buscaremos, no ordenamento brasileiro, as hipóteses jurídicas de sua ocorrência, desbravando conceitos e estabelecendo as necessárias definições terminológicas. Nesse mister, esforços serão envidados a fim de que sedimentadas confusões conceituais sejam desveladas, traçando-se as bases teóricas para um futuro tratamento processual autônomo (e, em consequência, mais adequado e útil) às declarações do corréu. 
O Capítulo 4 destina-se à sindicância do direito ao confronto aplicado às declarações do corréu em algumas selecionadas jurisdições estrangeiras e internacionais. O objetivo principal será a observação geral sobre a implementação e a aplicação deste direito em outras experiências, a fim de perquirir a viabilidade da concepção de um mínimo a caracterizar a proteção do direito ao confronto em um sistema processual penal interno.

Por fim, no Capítulo 5, voltaremos a pena ao nosso direito processual penal, quando investigaremos as normas abstratas e a prática jurídica para delas extrair o paradigma brasileiro do tratamento dispensado ao direito ao confronto e às declarações do corréu. Dentre os objetivos, não poderiam faltar uma análise das consequências jurídicas da violação ao direito ao confronto, e uma visão sistêmica e conclusiva a respeito da implementação (formal e material) do direito ao confronto, enquanto direito humano fundamental, no sistema processual penal brasileiro.

Eis, pois, o tema, os limites e o plano geral da obra. 


\section{CONCLUSÃO}

Por todo o dispendido ao longo da presente pesquisa, é possível apresentar, de maneira sintética, aquilo que de mais útil se observou e as conclusões atingidas.

1. As origens históricas do direito ao confronto são consideradas obscuras. Não obstante, extensas pesquisas doutrinárias apontam que o direito ao confronto foi concebido em reação às condenações criminais baseadas em testemunhos obtidos secretamente, de maneira unilateral pelo Estado, sem transparência, sem possibilidade de presença do imputado, apresentados de maneira escrita em julgamento.

2. O direito ao confronto possui natureza jurídica de direito fundamental. Está estampado em diversas Constituições, como a norte-americana (Sexta Emenda) e a italiana, bem como consta de diversos tratados internacionais que tutelam direitos humanos, como é o caso da CEDH, da CADH e do PIDCP. Pela assinatura desses dois últimos tratados, o Brasil incorporou o direito ao confronto como norma materialmente constitucional ao seu ordenamento, assumindo, perante a comunidade internacional, o compromisso de implementá-lo, assegurá-lo e protegê-lo.

3. De sua concepção juspolítica extrai-se que o direito ao confronto impõe que o saber testemunhal contrário ao réu seja transmitido ao processo em atenção ao paradigma de seu conteúdo. Esse paradigma confrontativo é um modelo teórico aqui adotado, segundo o qual o conhecimento probatório incriminador deve ser apresentado (i) em audiência pública, (ii) na presença do juiz natural, (iii) na presença do acusado, (iv) com o compromisso do declarante em dizer a verdade, (v) com a identidade do declarante revelada ao acusado, e (vi) com a oportunidade de inquirição oral direta.

4. O direito ao confronto é incindível em um momento processual específico, qual seja, a produção, em juízo, da prova testemunhal contrária ao réu. Por outro lado, para se assegurar a necessária e ampla proteção deste direito, não se pode restringir sua incidência ao conhecimento probatório de quem formalmente é considerado testemunha. Assim, para fins de incidência do direito ao confronto, demonstrou-se a necessidade de se adotar uma acepção ampla do conceito de testemunha, a abarcar qualquer fonte pessoal de prova que possa transmitir ao processo declarações contrárias ao acusado. Nessa acepção ampla, estão também incluídos os peritos, as vítimas, o corréu incriminador etc. 
5. A estrutura normativa do direito ao confronto é de norma-princípio. Tal direito não possui um caráter absoluto. Desse modo, diante de colisões com outros interesses de mesma hierarquia, é possível o direito ao confronto ceder, permitindo-se legítimas restrições em seu âmbito de proteção.

6. Especificamente nas situações em que a "testemunha contrária" é um corréu (em acepção ampla), foram traçados dois sentidos para a expressão “declarações do corréu” delimitação necessária aos estudos posteriormente empreendidos.

7. Em um primeiro sentido, as declarações do corréu são elementos de prova, correspondendo aos dados objetivos que carregam em seu conteúdo informações prejudiciais à posição processual do réu incriminado. Essas informações, para além de contrárias ao réu, são informações verdadeiramente nocivas. Esse enorme prejuízo justifica-se, de um lado, pela proximidade do corréu em relação aos fatos objeto da imputação, o que muitas vezes expressa um conhecimento sem o qual a tese acusatória não é possível sequer restar demonstrada. De outro, justifica-se pela posição de titular de direitos da pessoa criminalmente acusada, o que lhe permite falsear e mentir, para obter benefícios penais ou se esquivar de qualquer responsabilidade penal mais gravosa para si. Esse "rosto dúplice de Jano" traduz uma possibilidade real de erro judiciário na decisão que se ampara nas declarações do corréu.

8. Em um segundo sentido, as declarações do corréu podem ser meio de prova, na medida em que serão as atividades através das quais os elementos de prova serão apresentados ao julgador de mérito. Esse "meio de prova gênero" congrega o interrogatório judicial e a tomada de declarações de um imputado em procedimento conexo.

9. O estudo de nosso tema-problema na perspectiva de outras jurisdições estrangeiras e internacionais permitiu-nos traçar paralelos, que se mostraram pertinentes e cooperativos à formação da base teórica ao enfrentamento do paradigma confrontativo brasileiro e da própria análise da incorporação do direito ao confronto em nosso ordenamento.

10. Nos EUA, o direito ao confronto, de acordo com a concepção atual da Suprema Corte, traçada em Crawford v. Washington, torna inadmissível qualquer declaração testemunhal contrária ao acusado, a menos que o declarante compareça em juízo, ou, se o declarante não estiver disponível por motivos justificáveis, que o acusado tenha tido uma oportunidade prévia de proceder ao cross-examination. Ao lado desse precedente, em 
relação às declarações do corréu, analisou-se a Bruton rule, traçada pela Suprema Corte no julgamento do caso Bruton v. United States. Por esse precedente, a confissão extrajudicial de um corréu é inadmissível como prova para incriminar outro réu, por violação à Sexta Emenda.

11. Pelo estudo das jurisdições inglesa e italiana, a principal constatação útil a ser registrada nessas sintéticas notas conclusivas é a respeito da primazia do paradigma confrontativo como forma de transferir ao julgador de mérito o saber de natureza testemunhal contrário ao réu. Nessas jurisdições, o julgador de mérito, via de regra, não toma contato prévio com os elementos de prova testemunhal (em acepção ampla) produzidos extrajudicialmente. A despeito das várias exceções, seus sistemas processuais penais assentam-se de modo a primeiro se envidar esforços para a produção da prova em atenção ao direito ao confronto. Assim, pode-se afirmar que, nesses países, a regra geral é, primeiro, a apresentação do conhecimento probatório incriminador em atenção ao paradigma confrontativo. Como exceção, declarações não confrontadas, produzidas extrajudicialmente, poderão ser apresentadas como prova acusatória.

12. Após, foram analisadas as jurisprudências do TEDH, do CDHNU e da CIDH. Essas jurisdições internacionais analisam o direito ao confronto como essencial para um processo justo, imergindo-o como manifestação da paridade de armas e do devido processo legal. Contudo, nenhuma dessas instâncias apresenta um verdadeiro conteúdo para a interpretação de suas cláusulas de confronto, deixando à discricionariedade das jurisdições domésticas a incumbência de traçar suas próprias regras para proteção deste direito fundamental.

13. O paradigma confrontativo e as declarações do corréu foram, então, analisados à luz do ordenamento processual penal brasileiro. Pode-se observar que o aparato legislativo nacional, não obstante a inexistência de referência interna a uma cláusula de confronto, traduz satisfatório atendimento ao modelo teórico de aplicação deste direito fundamental. Também aqui se admitem algumas legítimas restrições ao direito ao confronto. Por exemplo, a determinação da retirada do réu da sala de audiências durante o interrogatório do corréu incriminador, caso existam concretas ações do primeiro no sentido de intimidar ou ameaçar o segundo e com isso interferir na idoneidade da colheita da prova. Outro exemplo de legítima restrição é a produção da prova em audiência em segredo de justiça, quando justificável. Por outro lado, há restrições inconstitucionais, como é o caso do completo anonimato do corréu e da adoção do revogado sistema presidencialista como procedimento 
probatório para a produção da prova testemunhal (em acepção ampla). À parte de eventuais patologias, a conclusão foi pelo adequado paradigma confrontativo em solo brasileiro, não obstante passível de desejosos aperfeiçoamentos epistêmicos e legislativos.

14. A aplicação do direito ao confronto em relação às declarações do corréu leva à sua potencial colisão com o direito ao silêncio deste último. Ambos são direitos de mesma hierarquia, os quais devem ser acomodados no sistema de modo a que ambos sejam, em máxima medida possível, assegurados e protegidos. Nessa colisão, contudo, percebe-se um antagonismo extremo: dialética comunicacional vs. ausência de comunicação. Todavia, o exercício do direito ao silêncio é discricionário de seu titular, enquanto que o direito ao confronto não depende apenas da vontade de seu titular em realizar um exercício defensivo. Dessa maneira, cabe à lei a solução da colisão, estipulando previamente em tais e quais situações o corréu incriminador deverá responder às perguntas da defesa do réu incriminado, sem possibilidade de exercitar seu direito de se calar. Nesse sentido, a única norma em vigor a privilegiar o direito ao confronto é o $\S 14$ do art. $4^{\circ}$ da Lei $n^{\circ} 12.850 / 13$. Nas demais hipóteses, deve ser assegurado ao corréu a faculdade de não responder às perguntas que lhe forem formuladas, sempre que o processo no qual for depor guardar um vínculo probatório com o processo no qual é formalmente acusado.

15. Como metodologia de enfrentamento do tema-problema, verificamos ser necessário delimitar, em um caso concreto, as declarações confrontadas e as declarações não confrontadas. Em apertada síntese, declarações confrontadas seriam aquelas fixadas no processo em atenção ao paradigma confrontativo, ainda que esse tenha sido legitimamente restringido. Por outro lado, declarações não confrontadas seriam aquelas produzidas fora do paradigma confrontativo e carentes de legítima justificativa para sua utilização. Como exemplo, as declarações não confrontadas poderiam vir a ser o termo de interrogatório policial do corréu; termos de colaboração premiada do corréu; os resultados de interceptação telefônica que contenham conversas do corréu; e o termo de declarações do corréu (em acepção ampla) juntado aos autos como prova emprestada.

16. Para que declarações produzidas fora do paradigma confrontativo possam ser utilizadas como prova, é necessário existir um bom motivo (regra de necessidade) para impor tamanha restrição ao direito ao confronto. De todas as possibilidades que envolvem a "ausência" do corréu em juízo (não comparecimento para depor ou exercício do direito ao silêncio), concluiu-se que somente atos ilícitos do réu que geram a impossibilidade material da presença do corréu (e.g.: homicídio consumado) podem atender à regra da necessidade. 
17. Em qualquer outra hipótese, a restrição não passa pelo filtro da regra da proporcionalidade, uma vez que o sistema possui numerosas outras alternativas que imporão menores restrições aos direitos fundamentais em jogo. Por isso, nesses casos, as declarações não confrontadas do corréu incriminador não poderão ser valoradas pelo juiz ao decidir o mérito da causa. Esses elementos são abarcados por uma proibição de valoração independente, cujo fundamento constitucional é o direito ao confronto. Na prática, qualquer afirmação valorativa, que indique que as declarações não confrontadas do corréu serviram à formação do convencimento judicial, gera nulidade da sentença. E, se os demais elementos dos autos, sozinhos, não suportarem a condenação, a absolvição se impõe.

18. Não obstante a conclusão de que, no plano abstrato das normas processuais penais, o paradigma confrontativo brasileiro satisfaz ao mínimo estipulado pelo direito ao confronto, reconhece-se que a proibição de valoração independente não impede, por completo, as contaminações do juiz por essas declarações não confrontadas - ainda que possa contê-las (as contaminações) em maior grau. Isso porque, pela estrutura do sistema processual penal brasileiro, as declarações não confrontadas chegarão ao julgador de mérito, quase sempre, antes de qualquer produção probatória de acordo com o paradigma confrontativo.

19. Os fundamentos do direito ao confronto são pelo primado desta forma de apresentação da prova ao julgador de mérito. Não basta que alguma produção de prova ocorra de acordo com os corolários do direito ao confronto. É necessário que o paradigma confrontativo seja $a$ forma como a prova é produzida. Ao não conceber o primado desta forma como a "regra de primeiro contato" do julgador com o conhecimento probatório incriminador, invariavelmente são mantidas todas as portas abertas para que, mesmo que inconscientemente, condene-se um cidadão com base em elementos de convicção produzidos unilateralmente pelo Estado, a portas fechadas, sem possibilidade de vigilância pública e transparente contra arbitrariedades e abusos, sem a presença do acusado ou seu defensor técnico. Ou seja, essa estrutura mantém viva a causa que historicamente deu fundamento juspolítico à concepção do direito ao confronto como direito fundamental.

20. Por essas razões, afirmou-se que o direito ao confronto é mais um motivo que aponta a necessidade de um novo CPP, redigido em conformidade com a CF e com os tratados de direitos humanos assinados pelo Brasil. Enquanto não for revogada a prevenção do juiz da fase de investigação preliminar; enquanto não for implementada a regra geral de primeiro contato com a prova aquela produzida de acordo com o paradigma confrontativo; 
e enquanto não existir um genuíno juízo de admissibilidade da prova, o satisfatório paradigma confrontativo brasileiro perde todo seu significado.

21. Em suma síntese, o direito ao confronto, no atual processo penal brasileiro, resta formalmente assegurado, mas material e sistemicamente negado. 


\section{BIBLIOGRAFIA}

ACADEMIA DAS CIÊNCIAS DE LISBOA. Dicionário da língua portuguesa contemporânea. V. 1. Lisboa: Verbo, 2001.

ALEXY, Robert. Teoria dos direitos fundamentais. Trad. port. Virgílio Afonso da Silva. São Paulo: Malheiros, 2015.

ALMEIDA JÚNIOR, João Mendes de. O processo criminal brazileiro. 3. ed., v. 1. Rio de Janeiro: Baptista de Souza, 1920.

ALMEIDA, Joaquim Canuto Mendes de. A contrariedade na instrução criminal. São Paulo: Saraiva, 1937.

ALTAVILlA, Enrico. Psicologia judiciária. 4. ed., v. 3. Coimbra: Armenio Amado, 1959.

AMBOS, Kai. As vedações de utilização das provas no processo penal alemão. Trad. esp. Óscar Julián Guerrero Peranta, trad. port. Marcellus Polastri Lima. In: AMBOS, Kai; e LIMA, Marcellus Polastri. O processo acusatório e a vedação probatória: Perante as realidades alemã e brasileira. Porto Alegre: Livraria do Advogado, 2009, pp. 81-125.

AMODIO, Ennio. Garanzie oggettive per la pubblica accusa?: A proposito di indagini difensive e giudizio abbreviato nel quadro costituzionale. In: Cassazione Penale, v. 50, n. 1, 2010, pp. 17-23.

. Giusto processo, diritto al silenzio e obblighi di verità dell'imputato sul fatto altrui. In: Cassazione Penale, v. 41, n. 12, 2001, pp. 3587-601.

ANDRADE, Manuel da Costa. Sobre as proibições de prova em processo penal. 1. ed. reimp. Coimbra: Coimbra, 2013.

ANDREWS, Johan; e HIRST, Michael. Andrews \& Hirst on Criminal Evidence. 3. ed. London: Sweet \& Maxwell, 1997.

ANJOS, Margarida dos; e FERREIRA, Marina Baird (Coords.). Novo Aurélio Século XXI: O dicionário da língua portuguesa - Aurélio Buarque de Holanda Ferreira. 3. ed. Rio de Janeiro: Nova Fronteira, 1999.

ANTUNES, Maria João. Direito ao silêncio e leitura em audiência de declarações do arguido. In: Sub Judice: Justiça e Sociedade, v. 4, 1992, pp. 25-26.

AQUINO, José Carlos Xavier de. A prova testemunhal no processo penal brasileiro. 3. ed. São Paulo: Saraiva, 1995.

ARANHA, Adalberto José de Camargo. Da prova no processo penal. 6. ed. São Paulo: Saraiva, 2004.

ARANTES FILHO, Marcio Geraldo Britto. $O$ cross-examination como procedimento probatório para produção de prova testemunhal no direito processual penal brasileiro. Tese (Doutorado). Faculdade de Direito da USP, São Paulo, 2016, 250 f. 
ASHWORTH, Andrew; e REDMAYNE, Mike. Criminal process. 4. ed. Oxford: Oxford University, 2010.

ASÚA, Luis Jiménez de. La recompensa como prevención general: El derecho premial. Madrid: Reus, 1915.

AZEVEDO, David Teixeira de. Delação premiada e direito de defesa. In: Boletim IBCCRIM, v. 22, n. 265,2014 , pp. 4-5.

. O interrogatório do réu e o direito ao silêncio. In: AZEVEDO, David Teixeira de. Atualidades no direito e processo penal. São Paulo: Método, 2001, pp. 133-150.

AZEVEDO, Luiz Carlos de. Sistemas processuais penais: Acusatório, inquisitivo, misto origens, distorções, atualidades. In: Revista do Advogado, v. 24, n. 78, 2004, pp. 49-52.

AZEVEDO, Vicente de Paulo Vicente de. Curso de direito judiciário penal dado no Faculdade Paulista de Direito. V. 2. São Paulo: Saraiva, 1958.

BADARÓ, Gustavo. Correlação entre acusação e sentença. 2. ed. São Paulo: Revista dos Tribunais, 2009.

. Juiz natural no processo penal. São Paulo: Revista dos Tribunais, 2014.

. Ônus da prova no processo penal. São Paulo: Revista dos Tribunais, 2003.

. Processo penal. 3. ed. São Paulo: Revista dos Tribunais, 2015.

. Provas atípicas e provas anômalas: Inadmissibilidade da substituição da prova testemunhal pela juntada de declarações escritas de quem poderia ser testemunha. In: YARSHELL, Flávio Luiz; e MORAES, Maurício Zanoide de (Orgs.). Estudos em homenagem à Professora Ada Pellegrini Grinover. São Paulo: DPJ, 2005, pp. 341-52.

; e BOTTINI, Pierpaolo Cruz. Lavagem de dinheiro: Aspectos penais e processuais penais. 2. ed. São Paulo: Revista dos Tribunais, 2013.

BAKER, R. W. The hearsay rule. London: Sir Isaac Pitman \& Sons, 1950.

BAPTISTA, Francisco das Neves. O mito da verdade real na dogmática do processo penal. Rio de Janeiro: Renovar, 2001.

BARGIS, Marta. Le dichiarazioni di persone imputate in un procedimento connesso. Milano: Giuffrè, 1994.

BARNES, Rebecca. Introductory note to the European Court of Human Rights: Al-Khawaja \& Tahery v. United Kingdom. In: International Legal Materials, v. 51, n. 3, 2012, pp. 47779.

BARROS, Marco Antonio de. A busca da verdade no processo penal. 4. ed. São Paulo: Revista dos Tribunais, 2013.

Lavagem de dinheiro e obrigações civis correlatas. 3. ed. São Paulo: Revista dos Tribunais, 2012.

BARTELS, Robert. The hearsay rule, the confrontation clause, and reversible error in criminal cases. In: Arizona State Law Journal, v. 26, n. 4, 1994, pp. 967-86. 
BASSIOUNI, M. Cherif. Human rights in the context of criminal justice: Identifying international procedural protections and equivalent protections in national constitutions. In: Duke Journal of Comparative \& International Law, v. 3, n. 2, 1993, pp. 235-97.

BECHARA, Fábio Ramazzini. Colaboração processual: Legalidade e valor probatório. In: Boletim IBCCRIM, v. 23, n. 269, 2015, pp. 6-7.

BEIJER, Annemarieke; COBLEY, Cathy; e KLIP, Andre. Witness evidence, article 6 of the European Convention on Human Rights and the principle of open justice. In: HARDING, Christopher et al. (Orgs.). Criminal justice in Europe: A comparative study. Oxford: Clarendon, 1995, pp. 283-300.

BELEZA, Teresa Pizarro. "Tão amigos que nós éramos": O valor probatório do depoimento do co-arguido no processo penal português. In: Revista do Ministério Público de Lisboa, v. 19, n. 19, 1998, pp. 39-60.

BELLIN, Jeffrey. The incredible shrinking confrontation clause. In: Boston University Law Review, v. 92, n. 6, 2012, pp. 1865-1916.

BENADI, Gabrielle. All aboard the Bruton line. In: Journal of Criminal Law and Criminology, v. 89, n. 3, 1999, pp. 837-65.

BENTHAM, Jeremy. Rationale of judicial evidence: Specially applied to English practice. V. 1. London: Hunt and Clarke, 1827.

. Théorie des peines et des récompenses. 3. ed., 2 vv. Paris: Bossange Freres, 182526.

BERGER, Margaret. The deconstitutionalization of the confrontation clause: A proposal for a prosecutorial restraint model. In: Minnesota Law Review, v. 76, n. 3, 1992, pp. 557-613.

BERTOLINO, Pedro. Código de Procedimiento Penal de la Provincia de Buenos Aires. 2. ed. Buenos Aires: Depalma, 1989.

El debido proceso penal. La Plata: Platense, 1986.

BEVERE, Antonio. La chiamata di correo: Itinerario del sapere dell'imputato nel processo penale. 2. ed. Milano: Giuffrè, 2001.

BIRCH, Diane; e HIRST, Michael. Interpreting the new concept of hearsay. In: Cambridge Law Journal, v. 69, n. 1, 2010, pp. 72-97.

BITENCOURT, Cezar Roberto. Tratado de direito penal: Parte geral. 15. ed., v. 1. São Paulo: Saraiva, 2010.

; e BREDA, Juliano. Crimes contra o Sistema Financeiro Nacional e contra o mercado de capitais. Rio de Janeiro: Lumen Juris, 2010.

; e BUSATO, Paulo César. Comentários à lei de organização criminosa: Lei $n$. 12.820/2013. São Paulo: Saraiva, 2014.

BITTAR, Walter Barbosa. A delação premiada no Brasil. In: BITTAR, Walter Barbosa. Delação premiada: Direito estrangeiro, doutrina, jurisprudência. Rio de Janeiro: Lumen Juris, 2011, pp. 89-217. 
. Observações necessárias. In: BITTAR, Walter Barbosa. Delação premiada: Direito estrangeiro, doutrina, jurisprudência. Rio de Janeiro: Lumen Juris, 2011, pp. 1-6.

BLACK, Henry Campbell. Black's Law Dictionary. 6 ed. St. Paul: West, 1990.

BLACK, Michael. Cross-examination: The greatest legal engine for the discovery of truth A comparative analysis of the American and English rules of cross-examination. In: Southern University Law Review, v. 15, n. 2, 1988, pp. 397-405.

BLUMENTHAL, Jeremy. Reading the text of the confrontation clause: To be or not to be. In: University of Pennsylvania Journal of Constitutional Law, v. 3, n 2, 2001, pp. 722-49.

BONAVIDES, Paulo. Curso de direito constitucional. 22. ed. São Paulo: Malheiros, 2010.

BONETTI, Michele. La chiamata di correo: Rasegna critica. In: L'indice Penale, v. 20, n. 1, 1986, pp. 57-79.

BORGES, Clara Maria Roman. Jurisdição penal e normalização. V. 5. Coleção Jacinto Nelson de Miranda Coutinho. Florianópolis: Conceito, 2010.

BOYER, Allen. The trial of Sir Walter Ralegh: The law of treason, the trial of treason and the origins of the confrontation clause. In: Mississippi Law Journal, v. 74, n. 3, 2005, pp. 869-901.

BROWN, Joel. The confrontation clause and the hearsay rule: A problematic relationship in need of a practical analysis. In: Florida State University Law Review, v. 14, n. 4, 1987, pp. 949-73.

BRUNI, Luigino. On virtues and awards: Giacinto Dragonetti and the tradition of economia civile in enlightenment Italy. In: Journal of the History of Economic Thought, v. 35, n. 4, 2013, pp. 517-35.

CABRAL, Antonio do Passo. Convenções processuais: Entre publicismo e privatismo. Tese (Livre-Docência). Faculdade de Direito da USP, São Paulo, 2015, 308 f.

CANOTILHO, José Joaquim Gomes. Direito constitucional e teoria da Constituição. 7. ed., 3. reimp. Coimbra: Almedina, 2006.

CARLSON, Ronald L.; e CARLSON, Michael S. Unconstitutionality and the rule of wideopen cross-examination: Encroaching on the Fifth Amendment when examining the accused. In: John Marshall Law Journal, v. 7, n. 2, pp. 269-305.

CARVALHO, Natália Oliveira de. A delação premiada no Brasil. Rio de Janeiro: Lumen Juris, 2009.

CARVALHO, Salo de. A política criminal de drogas no Brasil: Estudo criminológico e dogmático da Lei 11.343/06. 5. ed. Rio de Janeiro: Lumen Juris, 2010.

CASARA, Rubens R. R. Juiz das garantias: Entre uma missão de liberdade e o contexto de repressão. In: COUTINHO, Jacinto Nelson de Miranda; e CARVALHO, Luis Gustavo Grandinetti Castanho de (Orgs.). O novo processo penal à luz da Constituição: Análise crítica do Projeto de Lei $n^{o}$ 156/2009, do Senado Federal. Rio de Janeiro: Lumen Juris, 2010, pp. 167-76. 
CASIRAGHI, Roberta. Testimoni assenti: La Grande Camara ridefinisce la regola della “prova unica o determinante”. In: Cassazione Penale, v. 52, n. 9, 2012, pp. 3115-31.

CATENA, Víctor Moreno. La defensa en el proceso penal. 1. ed. Madrid: Civitas, 1982.

CEREZO MIR, José. Derecho penal: Parte general. 1. ed. São Paulo: Revista dos Tribunais, 2007.

CHIARA, Giuseppe di. Chiamata di correo, garantismo collettivo e diritto di difesa. In: Rivista Italiana di Diritto e Procedura Penale, v. 30, n. 2, 1987, pp. 217-36.

CHOO, Andrew L.-T. Abuse of process and judicial stays of criminal proceedings. 2. ed. Oxford: Oxford University, 2008.

. Hearsay and confrontation in criminal trials. Oxford: Clarendon, 1996.

CHOUKR, Fauzi Hassan. Código de Processo Penal: Comentários consolidados \& crítica jurisprudencial. 7. ed., v. 1. Belo Horizonte: D’Plácido, 2017.

CINTRA, Antonio Carlos de Araújo; GRINOVER, Ada Pellegrini; e DINAMARCO, Cândido Rangel. Teoria geral do processo. 25. ed. São Paulo: Malheiros, 2009.

CLAPHAM, Nicholas. Hearsay evidence and the demise of absolute rules. In: The Journal of Criminal Law, v. 80, n. 4, 2016, pp. 220-23.

COMOGLIO, Luigi Paolo. La garanzia costituzionale dell'azione ed il processo civile. Padova: Cedam, 1970.

CONTI, Carlotta. L'imputato nel procedimento connesso: Diritto al silenzio e obbligo di verità. Padova: Cedam, 2003.

CORDERO, Franco. Procedura penale. 4. ed. Milano: Giuffrè, 1998.

CÓRDOBA, Gabriela. Nemo tenetur se ipsum accusare: ¿principio de pasividad?. In: BAIGÚN, David (Org.). Estudios sobre la justicia penal: Homenaje al Profesor Julio B. J. Maier. 1. ed. Buenos Aires: Del Puerto, 2005, pp. 279-301.

CORSO, Piermaria. Diritto al silenzio: Garanzia da difendere o ingombro processuale da rimuovere. In: L'indice Penale, v. 2, n. 3, 1999, pp. 1077-1094.

COSTA, Moacyr Lobo da. Confissão e reconhecimento do pedido. São Paulo: Saraiva, 1983.

COUCEIRO, João Claudio. A garantia constitucional do direito ao silêncio. São Paulo: Revista dos Tribunais, 2004.

COUTINHO, Jacinto Nelson de Miranda. Efetividade do processo penal e golpe de cena: Um problema às reformas processuais no Brasil. In: Boletim da Faculdade de Direito de Coimbra, v. 78, 2002, pp. 687-97.

. O papel do novo juiz no processo penal. In: COUTINHO, Jacinto Nelson de Miranda (Org.). Crítica à teoria geral do direito processual penal. Rio de Janeiro: Renovar, 2001, pp. 3-59.

CRYER, Robert. Witness evidence before international criminal tribunals. In: The Law and Practice of International Courts and Tribunals, v. 2, n. 3, 2003, pp. 411-39. 
D’AMICO. Silvio. Il collaboratore della giustizia. Roma: Laurus Robuffo, 1995.

DALE, Richard. Who killed Sir Walter Ralegh?. Brimscombe: The History, 2014.

DAMAŠKA, Mirjan. Evidence law adrift. New Haven: Yale University, 1997.

Evidentiary barriers to conviction and two models of criminal procedure: A comparative study. In: University of Pennsylvania Law Review, v. 121, n. 3, 1973, pp. 50689.

. Models of criminal procedure. In: Zbornik Pravnog Fakulteta u Zagrebu, v. 51, nn. 3-4, 2001, pp. 477-506.

. Of hearsay and its analogues. In: Minnesota Law Review, v. 76, n. 3, 1992, pp. 425-

58.

Presentation of evidence and factfinding precision. In: University of Pennsylvania Law Review, v. 123, n. 5, 1975, pp. 1083-106.

. The uncertain fate of evidentiary transplants: Anglo-american and continental experiments. In: American Journal of Comparative Law, v. 45, n. 4, 1997, pp. 839-52.

DAVENPORT, David S. The confrontation clause and the co-conspirator exception in criminal prosecutions: A functional analysis. In: Harvard Law Review, v. 85, n. 7, 1972, pp. 1378-1407.

DAWSON, Robert O. Joint trials of defendants in criminal cases: An analysis of efficiencies and prejudices. In: Michigan Law Review, v. 77, n. 6, 1979, pp. 1379-1455.

DE SANCTIS, Fausto. Crime organizado e lavagem de dinheiro: Destinação de bens apreendidos, delação premiada e responsabilidade social. São Paulo: Saraiva, 2009.

DEMBOUR, Marie-Bénédicte; e HASLAM, Emily. Silencing hearings?: Victims-witnesses at war crimes trials. In: European Journal of International Law, v. 15, n. 1, 2004, pp. 15177.

DENNIS, Ian. The right to confront witnesses: Meanings, myths and human rights. In: Criminal Law Review, v. 57, n. 4, 2010, pp. 255-74.

DERRYBERRY, George Merton. Confrontation: Prior testimony, confessions and the Sixth Amendment. In: Tennessee Law Review, v. 36, n. 2, 1969, pp. 382-99.

DEZEM, Guilherme Madeira. Da prova penal: Tipo processual, provas típicas e atípicas. Campinas: Millennium, 2008.

. Produção da prova testemunhal e interrogatório: Correlações necessárias. In: Boletim IBCCRIM, v. 17, n. 207, 2010, pp. 6-7.

DI MARTINO, Corrada; e PROCACCIANTI, Teresa. La chiamata di correo. Padova: Cedam, 2007. ; e . La prova testimoniale nel processo penale. 2. ed. Padova: Cedam, 2010.

DIAS, Jorge de Figueiredo. Direito processual penal. Coimbra: Coimbra, 2004. 
DICKINSON, Joshua. The confrontation clause and the hearsay rule: The current state of a failed marriage in need of a quick divorce. In: Creighton Law Review, v. 33, n. 4, 2000, pp. 763-820.

DIEZ, Manuel Quintanar. La justicia penal y los denominados “arrepentidos”. Madrid: Edersa, 1996.

DINAMARCO, Cândido Rangel. Fundamentos do processo civil moderno. 6. ed., t. 1. São Paulo: Malheiros, 2010. Instituições de direito processual civil. 6. ed., v. 3. São Paulo: Malheiros, 2009. ; e LOPES, Bruno Vasconcelos Carrilho. Teoria geral do novo processo civil. São Paulo: Malheiros, 2016.

DiPACE, Steven B. A perspective on the decisional demise of the right of confrontation. In: Suffolk University Law Review, v. 7, n. 3, 1973, pp. 554-86.

DIPP, Gilson. A "delação" ou colaboração premiada: Uma análise do instituto pela interpretação da lei. Brasília: IDP, 2015. Disponível em: http://www.idp.edu.br/docman/ebooks/1043-delacao-ou-colaboracao-premiada/file. Acesso 04/12/2017.

DOAK, Jonathan; e McGOURLAY, Claire. Criminal Evidence in context. 4. ed. Abingdon: Routledge, 2015

DODSON, Margaret. Bruton on balance: Standardizing redacted codefendant confessions through Federal Rule of Evidence 403. In: Vanderbilt Law Review, v. 69, n. 3, 2016, pp. 803-43.

DOMINIONI, Oreste. La valutazione delle dichiarazioni dei pentiti. In: Rivista Italiana di Diritto e Procedura Penale, v. 41, n. 4, 1986, pp. 741-67.

Un nuovo idolum theatri: Il principio di non dispersione probatoria. In: Rivista Italiana di Diritto e Procedura Penale, v. 40, n. 3, 1997, pp. 736-73.

DOUGLASS, John G. Beyond admissibility: Real confrontation, virtual cross-examination and the right to confront hearsay. In: George Washington Law Review, v. 67, n. 2, 1999, pp. 191-272.

DRIPPS, Donald. Controlling the damage done by Crawford v. Washington: Three constructive proposals. In: Ohio State Journal of Criminal Law, v. 7, n. 2, 2010, pp. 521-62.

DUCLERC, Elmir. Direito processual penal. 3. ed. Rio de Janeiro: Lumen Juris, 2011.

DWORKIN, Ronald. A matter of principle. Cambridge: Harvard University, 1985.

ESPÍNOLA FILHO, Eduardo. Código de processo penal brasileiro anotado. 4. ed., v. 8. Rio de Janeiro: Borsoi, 1956.

ESPOSITO, Giovanni. Considerazioni sulla posizione del giudice nella cross-examination. In: Archivio Penale, v. 26, 1970, pp. 381-386. 
ESSADO, Tiago Cintra. Delação premiada e idoneidade probatória. In: Revista Brasileira de Ciências Criminais, v. 21, n. 101, 2013, pp. 203-227.

ESTELLITA, Heloisa. A delação premiada para a identificação dos demais coautores ou partícipes: Algumas reflexões à luz do devido processo legal. In: Boletim IBCCRIM, v. 17, n. 202, 2009, pp. 2-3.

FERNANDES, Antonio Scarance. O equilíbrio entre a eficiência e o garantismo e o crime organizado. In: Revista Brasileira de Ciências Criminais, v. 16, n. 70, 2008, pp. 229-268.

. Processo penal constitucional. 6. ed. São Paulo: Revista dos Tribunais, 2010.

. Reação defensiva à imputação. São Paulo: Revista dos Tribunais, 2002.

. Teoria geral do procedimento e o procedimento no processo penal. São Paulo: Revista dos Tribunais, 2005.

FEUCHS-MARKER, Marilyn. United States v. Inadi: Co-conspirators lose the battle between the confrontation clause and hearsay. In: Loyola of Los Angeles Law Review, v. 21, n. 2, 1988, pp. 543-80.

FLECK, Andrew. "At the time of his death": The contested narrative of Sir Walter Ralegh's beheading. In: TRACY, Larissa; e MASSEY, Jeff. Heads will roll: Decapitation in the Medieval and early Modern imagination. Leiden: Brill, 2012, pp. 235-60.

FLORIAN, Eugenio. Delle prove penali. V. 2. Milano: Vallardi, 1924.

FRANÇA, Rubens Limongi (Coord.). Enciclopédia Saraiva do Direito. V. 23. São Paulo: Saraiva, 1977.

FRANCO, Alberto Silva; LIRA, Rafael; e FÉLIX, Yuri. Crimes hediondos. 7. ed. São Paulo: Revista dos Tribunais, 2011.

FRICKE, David S. The Tenth Circuit reaffirms the Bruton rule. In: Washburn Law Journal, v. 30, n. 2, 1991, pp. 326-38.

FRIEDMAN, Richard D. 'Face to face': Rediscovering the right to confront prosecution witnesses. In: International Journal of Evidence \& Proof, v. 8, n. 1, 2004, pp. 1-30.

. Confrontation: The search of basic principles. In: Georgetown Law Journal, v. 86, n. 4, 1998, pp. 1011-43.

. Grappling with the meaning of 'testimonial'. In: Brooklyn Law Review, v. 71, n. 1, 2005, pp. 241-74.

. Is a forensic laboratory report identifying a substance as narcotic "testimonial"?. In: Preview of United States Supreme Court Cases, v. 36, n. 2, 2008, pp. 76-79.

. Rescued from the grave and then covered with mud: Justice Scalia and the unfinished restoration of the confrontation right. In: Minnesota Law Review Headnotes, v. 101, 2016, pp. 39-51.

. The confrontation clause re-rooted and transformed. In: Cato Supreme Court Review, v. 2003-2004, 2004, pp. 439-68. 
The confrontation right across the systemic divide. In: JACKSON, John D.; LANGER, Máximo; e TILLERS, Peter (Eds.). Crime, procedure and evidence in a comparative and international context: Essays in honour of Mirjan Damaška. Oxford: Hart, 2008, pp. 261-71.

Truth and its rivals in the law of hearsay and confrontation. In: Hastings Law Journal, v. 49, n. 3, 1998, pp. 545-64.

FRIEDMAN, Ruth. The confrontation clause in search of a paradigm: Has public policy trumped the Constitution?. In: Pace Law Review, v. 22, n. 2, 2002, pp. 455-508.

GALANTINI, Maria Novella. Giusto processo e garanzia costituzionale del contraddittorio nella formazione della prova. In: Processo Penale e Giustizia, v. 2, n. 2, 2012, pp. 1-12.

GARCIA, Alfredo. The winding path of Bruton v. United States: A case of doctrinal inconsistency. In: American Criminal Law Review, v. 26, n. 2, 1988, pp. 401-39.

GIACOMOLLI, Nereu José. A fase preliminar do processo penal: Crises, misérias e novas metodologias investigatórias. Rio de Janeiro: Lumen Juris, 2011.

GLOECKNER, Ricardo Jacobsen. Nulidades no processo penal: Introdução principiológica à teoria do ato processual irregular. 2. ed. Salvador: JusPodivm, 2015.

GOMES FILHO, Antonio Magalhães. A motivação das decisões judiciais. 2. ed. São Paulo: Revista dos Tribunais, 2013.

Direito à prova no processo penal. São Paulo: Revista dos Tribunais, 1997.

. Notas sobre a terminologia da prova (reflexos no processo penal brasileiro). In: YARSHELL, Flávio Luiz; e MORAES, Maurício Zanoide de (Orgs.). Estudos em homenagem à Professora Ada Pellegrini Grinover. São Paulo: DPJ, 2005, pp. 303-18.

. Provas - Lei 11.690, de 09.06.2008. In: MOURA, Maria Thereza de Assis (Coord.). As reformas no processo penal: As novas Leis de 2008 e os projetos de reforma. São Paulo: Revista dos Tribunais, 2008, pp. 246-297.

; e BADARÓ, Gustavo. Prova e sucedâneos de prova no processo penal brasileiro. In: Revista Brasileira de Ciências Criminais, v. 15, n. 65, 2007, pp. 175-208.

GOMES, Décio Alonso. Prova e imediação no processo penal. Salvador: JusPodivm, 2016.

GOMES, Luiz Flávio; e SILVA, Marcelo Rodrigues da. Organizações criminosas e técnicas especiais de investigação. Salvador: JusPodivm, 2015.

GOSS, Ryan. Criminal fair trial rights: Article 6 of the European Convention on Human Rights. Oxford: Hart, 2014.

GÖSSEL, Karl-Heinz. As proibições de prova no direito processual penal da República Federal da Alemanha. Trad. port. Manuel da Costa Andrade. In: Revista Portuguesa de Ciências Criminais, v. 2, n. 3, 1992, pp. 397-441.

GRAHAM, Kenneth. The right of confrontation and the hearsay rule: Sir Walter Raleigh loses another one. In: Criminal Law Bulletin, v. 8, 1972, pp. 99-144. 
GRAHAM, Michael H. Bruton v. United States: Limited admissibility and the rule of completeness. In: Criminal Law Bulletin, v. 41, n. 4, 2005, pp. 418-36.

GRANDE, Elisabetta. Italian Criminal Justice: Borrowing and resistance. In: The American Journal of Comparative Law, v. 48, n. 2, 2000, pp. 227-60.

GRECO FILHO, Vicente. Manual de processo penal. 7. ed. São Paulo: Saraiva, 2009.

. Tutela constitucional das liberdades. São Paulo: Saraiva, 1989.

; e RASSI, João Daniel. Lei de drogas anotada. 1. ed. São Paulo: Saraiva, 2007.

GREER, Brooks. Hearsay, the confrontation guarantee and related problems. In: Louisiana Law Review, v. 30, n. 4, 1970, pp. 651-72.

GREVI, Vittorio. Il diritto al silenzio dell'imputato sul fatto proprio e sul fatto altrui. In: Rivista Italiana di Diritto e Procedura Penale, v. 41, 1998, pp. 1129-50.

GRINOVER, Ada Pellegrini. Defesa, contraditório, igualdade e par conditio na ótica do processo de estrutura cooperatória. In: GRINOVER, Ada Pellegrini. Novas tendências do direito processual: De acordo com a Constituição de 1988. Rio de Janeiro: Forense Universitária, 1990, pp. 1-16.

Influência do Código de Processo Penal Modelo para Ibero-América na legislação latino-americana: Convergências e dissonâncias com os sistemas italiano e brasileiro. In: Revista Brasileira de Ciências Criminais, v. 1, n. 1, 1993, pp. 41-63.

. O interrogatório como meio de defesa (Lei 10.792/2003). In: Revista Brasileira de Ciências Criminais, v. 13, n. 53, 2005, pp. 185-200.

- O interrogatório como meio de defesa. In: GRINOVER, Ada Pellegrini. $O$ processo: Estudos \& pareceres. 2. ed. São Paulo: DPJ, 2009, pp. 378-89.

. Prova emprestada. In: GRINOVER, Ada Pellegrini. O processo em evolução. 2. ed. Rio de Janeiro: Forense, 1998, pp. 54-63.

; GOMES FILHO, Antonio Magalhães; e FERNANDES, Antonio Scarance. As nulidades no processo penal. 12. ed. São Paulo: Revista dos Tribunais, 2011.

GUIMARÃES, Marcello Ovidio Lopes. Delação premiada. In: GUIMARÃES, Marcello Ovidio Lopes. (Coord.). Nova lei de drogas comentada. São Paulo: Quartier Latin, 2007, pp. 223-230.

HADDAD, Carlos Henrique Borlido. Conteúdo e contornos do princípio contra a autoincriminação. 1. ed. Campinas: Bookseller, 2005.

HADDAD, James. Post-Bruton developments: A reconsideration of the confrontation rationale, and a proposal for a due process evaluation of limiting instructions. In: American Criminal Law Review, v. 18, n. 1, 1980, pp. 1-49.

HERRMANN, Frank R.; e SPEER, Brownlow M. Facing the accuser: Ancient and Medieval precursors of the confrontation clause. In: Virginia Journal of International Law, v. 34, n. 3, 1994, pp. 481-552. 
HIPP, Jason Portwood. Redacting the Constitution: Securing Bruton's confrontation protections for a codefendant during non-evidentiary counsel commentary. In: Columbia Human Rights Law Review, v. 44, n. 1, 2002, pp. 259-308.

IBÁÑEZ, Perfecto Andrés. Sobre o valor da imediação: Uma aproximação crítica. Trad. port. Lédio Rosa de Andrade. In: IBÁÑEZ, Perfecto Andrés; e ANDRADE, Lédio Rosa de (Orgs.). Valoração da prova e sentença penal. Rio de Janeiro: Lumen Juris, 2006, pp. 1-32.

JACKSON, John D. International developments on the right to confrontation: Searching for its core value. In: Criminal Law and Procedure Review, v. 1, 2011, pp. 61-72.

; e SUMMERS, Sarah. Confrontation with Strasbourg: UK and Swiss approaches to criminal evidence. In: Criminal Law Review, v. 60, n. 2, 2013, pp. 114-30. ; e The internationalisation of criminal evidence: Beyond the common law and the civil law traditions. Cambridge: Cambridge University, 2012.

JARDIM, Afrânio Silva. Poder Judiciário não deve ser refém de acordos de delação premiada do MP. In: Revista Consultor Jurídico, 18/10/15. Disponível em: http://www.conjur.com.br/2015-out-18/afranio-jardim-judiciario-nao-refem-acordosdelacao-premiada. Acesso em 10/07/16.

JESUS, Damásio Evangelista de. Estágio atual da "delação premiada" no direito penal brasileiro. In: Revista Magister de Direito Penal e Processual Penal, v. 2, n. 7, 2005, pp. 98102.

. Lei antidrogas anotada. 9. ed. São Paulo: Saraiva, 2009.

Nova lei antitóxicos - Lei n. 10.409/02: Mais confusão legislativa. In: Revista Cejap, v. 4, n. 6, 2003, pp. 12-13.

JEZER, Aviva. Right to confrontation in codefendant confession cases: Richardson v. Marsh and Cruz v. New York. In: Cornell Law Review, v. 74, n. 4, 1989, pp. 712-41.

JONAKAIT, Randolph. The origins of the confrontation clause: An alternative history. In: Rutgers Law Journal, v. 27, n. 1, 1995, pp. 77-168.

. The too-easy historical assumptions of Crawford v. Washington. In: Brooklyn Law Review, v. 71, n. 1, 2005, pp. 219-34.

KADISH, Mortimer R.; e DAVIS, Michael. Defending the hearsay rule. In: Law and Philosophy, v. 8, n. 3, 1989, pp. 333-352.

KAPLAN, Cheryl. The co-conspirator exemption from the hearsay rule and the confrontation clause of the Sixth Amendment: The Supreme Court resolves the conflict?. In: John Marshall Law Review, v. 20, n. 3, 1987, pp. 597-606.

KHALED JR., Salah. A busca da verdade no processo penal: Para além da ambição inquisitorial. São Paulo: Atlas, 2013.

LA CHINA, Sergio. L'esecuzione forzata e le disposizioni generali del codice di procedura civile. 2. ed. Milano: Giuffrè, 1970. 
LA GRASSERIE, Raoul De. Droit prémial et droit penal. In: La Scuola positiva, v. 10, 1900, pp. 385-402.

LAFER, Celso. A reconstrução dos direitos humanos: Um diálogo com o pensamento de Hannah Arendt. São Paulo: Companhia das Letras, 1988.

LANGBEIN, John H. Historical foundations of the law of evidence: A view from the Ryder Sources. In: Columbia Law Review, v. 96, n. 5, 1996, pp. 1168-1202.

. The origins of adversary criminal trial. New York: Oxford University, 2003.

LANGER, Máximo. In the beginning was Fortescue: On the intellectual origins of the adversarial and inquisitorial systems and common and civil law in comparative criminal procedure. In: ACKERMAN, Bruce; AMBOS, Kai; e SIKIRIĆ, Hrvoje (Eds.). Visions of Justice: Liber Amicorum Mirjan Damaška. Berlin: Duncker \& Humblot, 2016. Disponível em: https://ssrn.com/abstract=2703126. Acesso em 16/04/17.

. The rise of managerial judging in International Criminal Law. In: The American Journal of Comparative Law, v. 53, n. 4, 2005, pp. 835-910.

LARKIN, Murl. The right of confrontation: What next?. In: Texas Tech Law Review, v. 1, n. 1, 1969, pp. 67-86.

LAUAND, Mariana de Souza Lima. O valor probatório da colaboração processual. Dissertação (Mestrado). Faculdade de Direito da USP, São Paulo, 2008, 204 f.

LEAL, João José. A Lei $\mathrm{n}^{\circ}$ 10.409/02 e o instituto da delação premiada. In: Boletim IBCCRIM, v. 10, n. 118, 2002, pp. 2-4.

Inaplicabilidade das normas processuais previstas na Lei 10.409/02: Análise da jurisprudência sobre a matéria. In: Revista Jurídica, v. 52, n. 317, 2004, pp. 89-94.

LEVENTHAL, John. Is Bruton on life support in the aftermath of Crawford v. Washington?. In: American Journal of Criminal Law, v. 43, n. 1, 2015, pp. 1-18.

LIMA, Marcellus Polastri. Curso de processo penal. 8. ed. Brasília: Gazeta Jurídica, 2014.

LIMA, Renato Brasileiro. Curso de processo penal. Niterói: Impetus, 2013.

LININGER, Tom. The sound of silence: Holding batterers accountable for silencing their victims. In: Texas Law Review, v. 87, n. 5, 2009, pp. 857-912.

LONATI, Simone. Il diritto dell'accusato a "interrogare o fare interrogare" le fonti di prova a carico: Studio sul contraddittorio nella Convenzione Europea dei Diritti dell'Uomo e nel sistema processuale penale italiano. Torino: Giappichelli, 2008.

LONGENECKER, Rolla R. Some hints on the trial of a lawsuit. Rochester: Lawyers Cooperative, 1927.

LOPES JR., Aury. Direito processual penal. 12. ed. São Paulo: Saraiva, 2015.

2016.

. Fundamentos do processo penal: Introdução crítica. 2. ed. São Paulo: Saraiva,

. Prisões cautelares. 4. ed. São Paulo: Saraiva, 2013. 
; e RITTER, Ruiz. A imprescindibilidade do juiz das garantias para uma jurisdição penal imparcial: Reflexões a partir da teoria da dissonância cognitiva. In: Revista Magister de Direito Penal e Processual Penal, v. 13, n. 73, 2016, pp. 12-25.

LUPÁRIA, Luca. La confessione dell'imputato nel sistema processuale penale. Milano: Giuffrè, 2006.

LUSTY, David. Anonymous accusers: An historical \& comparative analysis of secret witnesses in criminal trials. In: Sydney Law Review, v. 24, n. 3, 2002, pp. 361-426.

MAFFEI, Stefano. Il diritto al confronto con l'accusatore. Piacenza: La Tribuna, 2003.

Negotiations 'on Evidence' and Negotiations 'on Sentence': Adversarial experiments in Italian Criminal Procedure. In: Journal of International Criminal Justice, v. 2, n. 4, 2004, pp. 1050-69.

Prova d'accusa e dichiarazioni di testimoni "assenti" in una recente sentenza della Corte Europea dei Diritti dell’Uomo. In: Cassazione Penale, v. 41, n. 10, 2001, pp. 284150.

. The right to confrontation in Europe: Absent, anonymous and vulnerable witnesses.

2. ed. Groningen: Europa Law, 2012.

MAIER, Julio B. J. Derecho procesal penal: Fundamentos. 2. ed. Buenos Aires: Del Puerto, 2004.

MALAN, Diogo Rudge. A sentença incongruente no processo penal. Rio de Janeiro: Lumen Juris, 2003.

. Direito ao confronto no processo penal. Rio de Janeiro: Lumen Juris, 2009.

MALATESTA, Nicola Framarino Dei. A lógica das provas em matéria criminal. Trad. port. Waleska Girotto Silverberg. V. 2. Campinas: Conan, 1995.

MANNHEIMER, Michael J. Zydney. Toward a unified theory of testimonial evidence under the Fifth and Sixth Amendments. In: Temple Law Review, v. 80, n. 4, 2007, pp. 1135-202.

MARCÃO, Renato Flávio. Novas considerações sobre o procedimento e a instrução criminal na Lei n. 10.409/2002: Nova lei antitóxicos. In: Cadernos Jurídicos, v. 3, n. 12, 2002, pp. 91-94.

MARCUS, Paul. Co-conspirator declarations: The Federal Rules of Evidence and other recent developments, from a criminal law perspective. In: American Journal of Criminal Law, v. 7, n. 3, 1979, pp. 287-322.

. The confrontation clause and co-defendant confessions: The drift from Bruton to Parker v. Randolph. In: University of Illinois Law Forum, v. 1979, n. 3, 1979, pp. 559-590.

MARINONI, Luiz Guilherme; e ARENHART, Sérgio Cruz. Prova. São Paulo: Revista dos Tribunais, 2009.

MARQUES, Antonio Sergio Peixoto. A colaboração premiada: Um braço da justiça penal negociada. In: Revista Magister de Direito Penal e Processual Penal, v. 10, n. 60, 2014, pp. 32-66. 
MARQUES, José Frederico. Elementos de direito processual penal. 2. ed., v. 1. Rio de Janeiro: Forense, 1965.

. Elementos de direito processual penal. 3. ed., v. 2. Campinas: Millennium, 2009.

MARTELETO FILHO, Wagner. $O$ direito à não autoincriminação no processo penal contemporâneo. Belo Horizonte: Del Rey, 2012.

MARTINS, Rui Cunha. O mapeamento processual da "verdade". In: PRADO, Geraldo; MARTINS, Rui Cunha; e CARVALHO, Luis Gustavo Grandinetti Castanho de. Decisão judicial: A cultura jurídica brasileira na transição para a democracia. Madrid: Marcial Pons, 2012, pp. 71-85.

MARZADURI, Enrico. Il diritto al silenzio del coimputato. In: Diritto Penale e Processo, v. 2, n. 12, 1998, pp. 1512-14.

MAY, Richard; POWLES, Steven; WAINE, Lydia; et al. May on Criminal Evidence. 6. ed. London: Sweet \& Maxwell, 2015.

MAYA, André Machado. O juiz de garantias no Brasil e nos países latino-americanos: Semelhanças e diferenças determinantes à estruturação democrática do sistema de justiça criminal. In: POSTIGO, Leonel González (Dir.); e BALLESTEROS, Paula R. (Coord.). Desafiando a inquisição: Ideias e propostas para a reforma processual penal no Brasil. Chile: CEJA, 2017, pp. 277-91.

MAZZUOLI, Valerio de Oliveira. Direitos humanos \& relações internacionais. Campinas: Aga Juris, 2000.

MEDINA, Cecília. The American Convention on Human Rights: Crucial rights and their theory and practice. Trad. ing. Peter Krupa. Cambridge: Intersentia, 2014.

MELCHIONDA, Achille. La chiamata di correo. In: Rivista Italiana di Diritto e Procedura Penale, v. 10, n. 1, 1967, pp. 148-208.

MELLO, Celso D. de Albuquerque. Curso de direito internacional público. 14. ed., v. 1. Rio de Janeiro: Renovar, 2002.

MENDES, João Guilherme Lages. Participação do acusado no interrogatório do corréu. In: Boletim IBCCRIM, v. 20, n. 233, 2012, pp. 6-7.

MENDONÇA, Andrey Borges de. A colaboração premiada e a criminalidade organizada: A confiabilidade das declarações do colaborador e seu valor probatório. In: SALGADO, Daniel de Resende; e QUEIROZ, Ronaldo Pinheiro de. A prova no enfrentamento à macrocriminalidade. 2. ed. Salvador: JusPodivm, 2016, pp. 231-77.

MENDRONI, Marcelo Batlouni. Crime organizado: Aspectos gerais e mecanismos legais. 4. ed. São Paulo: Atlas, 2012.

MESQUITA JÚNIOR, Sidio Rosa de. Incoerências da Lei n. 10.409/2002. In: Revista do Curso de Direito - Associação de Ensino Unificado do Distrito Federal, v. 4, n. 1, 2003, pp. 81-99. 
MILLER, Colin. Avoiding a confrontation?: How courts have erred in finding that nontestimonial hearsay is beyond the scope of the Bruton doctrine. In: Brooklyn Law Review, v. 77, n. 2,2012 , pp. 625-79.

MIRFIELD, Peter. Silence, confessions and improperly obtained evidence. Oxford: Clarendon, 1997.

MITTERMAIER, C. J. A. Tratado de la prueba en materia criminal. 9. ed. Madrid: Reus, 1959.

MOMMSEN, Teodoro. Derecho penal romano. Trad. esp. P. Dorado. Bogotá: Temis, 1991.

MONTANA, Riccardo. Procedural tradition in the Italian Criminal Justice System: The semi-adversarial Reform in 1989 and the inquisitorial cultural resistance to adversarial principles. In: International Journal of Evidence \& Proof, v. 20, n. 4, 2016, pp. 289-304.

MORAES, Maurício Zanoide de. Perplexidade de Jano: Quando o passado é mais presente do que o futuro (nova regulamentação do interrogatório e sua aplicabilidade na fase préprocessual). In: YARSHELL, Flávio Luiz; e MORAES, Maurício Zanoide de (Orgs.). Estudos em homenagem à Professora Ada Pellegrini Grinover. São Paulo: DPJ, 2005, pp. 365-81.

Presunção de inocência no processo penal brasileiro: Análise de sua estrutura normativa para a elaboração legislativa e para a decisão judicial. Rio de Janeiro: Lumen Juris, 2010.

Publicidade e proporcionalidade na persecução penal brasileira. In: FERNANDES, Antonio Scarance; ALMEIDA, José Raul Gavião de; e MORAES, Maurício Zanoide de (Coords.). Sigilo no processo penal: Eficiência e garantismo. São Paulo: Revista dos Tribunais, 2008, pp. 29-55.

MORAN, Leslie. Mass-mediated open justice: Court and Judicial Reports in the press in England and Wales. In: Legal Studies, v. 34, n. 1, 2014, pp. 143-66.

MORGAN, Edmund. Hearsay dangers and the application of the hearsay concept. In: Harvard Law Review, v. 62, n. 2, 1948, pp. 177-219.

MORO, Sérgio Fernando. Crime de lavagem de dinheiro. São Paulo: Saraiva, 2010.

MOSTELLER, Robert. Crawford v. Washington: Encouraging and ensuring the confrontation of witnesses. In: University of Richmond Law Review, v. 39, n. 2, 2005, pp. 511-626.

MOURA, Maria Thereza de Assis. Delação premiada. In: Revista Del Rey Jurídica, v. 8, n. 16, 2006, pp. 67-70.

; e BASTOS, Cleunice Valentim. Defesa penal: direito ou garantia. In: Revista Brasileira de Ciências Criminais, v. 1, n. 4, 1993, pp. 110-25.

; e MORAES, Maurício Zanoide de. Direito ao silêncio no interrogatório. In: Revista Brasileira de Ciências Criminais, v. 2, n. 6, 1994, pp. 133-47. 
MUELLER, Christopher B. Post-modern hearsay reform: The Importance of complexity. In: Minnesota Law Review, v. 76, n. 2, 1992, pp. 367-424. ; e KIRKPATRICK, Laird C. Evidence. 4. ed. Gaithersburg: Aspen, 2000.

MUNDAY, Roderick. Order in the indictment. In: Legal Studies, v. 1, n. 2, 1981, pp. 14664.

NANCE, Dale A. The best evidence principle. In: Iowa Law Review, v. 73, n. 2, 1988, pp. 227-97.

NASSIF, Aramis. Júri: Instrumento de soberania popular. Porto Alegre: Livraria do Advogado, 1996.

NESSON, Charles. The evidence or the event?: On judicial proof and the acceptability of verdicts. In: Harvard Law Review, v. 98, n. 7, 1985, pp. 1357-92.

NEUBURGER, Luisella de Cataldo. Esame e controesame nel processo penale. 2. ed. Padova: Cedam, 2008.

NICHOLLS, Mark. Sir Walter Ralegh's treason: A prosecution document. In: The English Historical Review, v. 110, n. 438, 1995, pp. 902-25.

. Treason's reward: The punishment of conspirators in the Bye Plot of 1603. In: The Historical Journal, v. 38, n. 4, 1995, pp. 821-42.

; e WILLIAMS, Penry. Sir Walter Raleigh: In life and legend. London: Continuum, 2011.

NORONHA, Edgard Magalhães. Curso de direito processual penal. 23. ed. São Paulo: Saraiva, 1995.

Notes. Richardson v. Marsh: Codefendant confessions and the demise of confrontation. In: Harvard Law Review, v. 101, n. 8, 1988, pp. 1876-94.

Notes. The admission of a codefendant's confession after Bruton v. United States: The questions and a proposal for their resolution. In: Duke Law Journal, v. 1970, n. 2, 1970, pp. 329-350.

NOVECK, Michael R. The death of confrontation clause originalism: Michigan v. Bryant. In: Harvard Civil Rights-Civil Liberties Law Review, v. 47, n. 1, 2012, pp. 251-71.

NUCCI, Guilherme de Souza. Código de processo penal comentado. 12. ed. São Paulo: Revista dos Tribunais, 2013. . Júri: Princípios constitucionais. São Paulo: Juarez de Oliveira, 1999. . O valor da confissão como meio de prova no processo penal. 2. ed. São Paulo: Revista dos Tribunais, 1999.

. Provas no processo penal. 3. ed. São Paulo: Revista dos Tribunais, 2013.

O'BRIAN JR., William. Confrontation: The defiance of the English Courts. In: International Journal of Evidence \& Proof, v. 15, n. 2, 2011, pp. 93-116. 
The right of confrontation: US and European perspectives. In: Law Quarterly Review, v. 121, n. 3, 2005, pp. 481-510.

O'CONNOR, Eoin. The right to confrontation, hearsay, and the European Court of Human Rights. In: University College Dublin Law Review, v. 14, 2014, pp. 78-99.

OSBORNE, Craig. Hearsay and the European Court of Human Rights. In: Criminal Law Review, v. 40, n. 4, 1993, pp. 255-67.

PACELLI, Engênio. Curso de processo penal. 17. ed. São Paulo: Atlas, 2013.

; e FISCHER, Douglas. Comentários ao Código de Processo Penal e sua jurisprudência. 8. ed. São Paulo: Atlas, 2016.

PASTOR, Daniel R. El plazo razonable en el proceso del estado de derecho: Una investigación acerca del problema de la excesiva duración del proceso penal y sus posibles soluciones. 1. ed. Buenos Aires: Ad-Hoc, 2002.

PAULESU, Pier Paolo. Giudice e parti nella "dialettica" della prova testimoniale. Torino: Giappichelli, 2002.

PAZIENZA, Vittorio. Il regime di utilizzabilità delle dichiarazioni rese dall'indagato in procedimento conesso. In: Cassazione Penale, v. 56, supl. 6, 2015, pp. 272-78.

PEDROSO, Fernando de Almeida. Processo penal: Direito de defesa - repercussão, amplitude e limites. 3. ed. São Paulo: Revista dos Tribunais, 2001.

PEREIRA, Frederico Valdez. Delação premiada: Legitimidade e procedimento. 2. ed. Curitiba: Juruá, 2014.

PINHO, Ana Cláudia Bastos de; e BRITO, Michelle Barbosa de. É possível controlar o livre convencimento motivado?: Quando a falta de uma teoria da decisão transforma a discricionariedade em "princípio". In: PINHO, Ana Cláudia Bastos de; DELUCHEY, JeanFrançois; e GOMES, Marcus Alan de Melo (Coords.). Tensões contemporâneas da repressão criminal. Porto Alegre: Livraria do Advogado, 2014, pp. 53-71.

PIOVESAN, Flávia. Direitos humanos e o direito constitucional internacional. 13. ed. São Paulo: Saraiva, 2012.

. Tratados internacionais de proteção dos direitos humanos e a Constituição Federal de 1988. In: Boletim IBCCRIM, v. 13, n. 153, 2005, pp. 8-9.

POLLITT, Daniel H. The right of confrontation: Its history and modern dress. In: Journal of Public Law, v. 8, n. 2, 1959, pp. 381-413.

PORCIÚNCULA, José Carlos. Inconstitucionalidades e inconsistências dogmáticas do instituto da delação premiada (art. $4^{\circ}$ da Lei 12.850/13). Disponível em: http://emporiododireito.com.br/inconstitucionalidades-e-inconsistencias-dogmaticas-doinstituto-da-delacao-premiada-art-4o-da-lei-12-85013/. Acesso em 06/04/2017.

PRADA, Ignacio Flores. El valor probatorio de las declaraciones de los coimputados. Madrid: Tecnos, 1998. 
PRADO, Geraldo. Prova penal e sistema de controles epistêmicos: A quebra da cadeia de custódia das provas obtidas por métodos ocultos. 1.ed. São Paulo: Marcial Pons, 2014.

. Sistema acusatório: A conformidade constitucional das leis processuais penais. 4. ed. Rio de Janeiro: Lumen Juris, 2006.

PRADO, Luiz Regis. Curso de direito penal brasileiro: Parte especial. 6. ed., v. 3. São Paulo: Revista dos Tribunais, 2010.

. Tratado de direito penal brasileiro: Parte geral. V. 1. São Paulo: Revista dos Tribunais, 2014.

QUEIJO, Maria Elizabeth. O direito de não produzir provas contra si mesmo: O princípio nemo tenetur se detegere e suas decorrências no processo penal. 2. ed. São Paulo: Saraiva, 2012.

QUEZADO, Paulo. Delação premiada. 1. ed. Fortaleza: Fortaleza, 2009.

RANDAZZO, Ettore. Insidie e strategie dell'esame incrociato. Milano: Giuffrè, 2008.

RASCOVSKI, Luiz. A (in)eficiência da delação premiada. In: Instituto de Estudos Avançados de Processo Penal ASF: Estudos de processo penal. São Paulo: Scortecci, 2011, pp. 141-97.

REDMAYNE, Mike. Hearsay and Human Rights: Al-Khawaja in the Grand Chamber. In: The Modern Law Review, v. 75, n. 5, 2012, pp. 865-78.

REED, Thomas J. Crawford v. Washington and the irretrievable breakdown of a union: Separating the confrontation clause from the hearsay rule. In: South Carolina Law Review, v. 56, n. 1, 2004, pp. 185-228.

REQUA, Marny. Absent witnesses and the UK Supreme Court: Judicial deference as judicial dialogue?. In: International Journal of Evidence \& Proof, v. 14, n. 3, 2010, pp. 208-31.

RIZZO, Francesco. L'elaboratizone della prova dichiarativa: Il metodo dell'esame incrociato. In: GAITO, Alfredo (Coord.). La prova penale: Le dinamiche probatorie e gli strumenti per l'accertamento giudiziale. V. 2. Torino: UTET, 2008, pp. 521-56.

ROBERTS, Paul; e ZUCKERMAN, Adrian. Criminal Evidence. 2. ed. Oxford: Oxford University, 2010.

ROGERS, Lance. Bruton doctrine inapplicable in cases involving interlocking confessions. In: DePaul Law Review, v. 28, n. 4, 1979, pp. 1161-88.

ROSSETTO, Enio Luiz. A confissão no processo penal. São Paulo: Atlas, 2001.

ROVEGNO, André. O sistema de provas no processo penal estadunidense. In: FERNANDES, Antonio Scarance; ALMEIDA, José Raul Gavião de; e MORAES, Maurício Zanoide de (Coords.). Provas no processo penal: Estudo comparado. São Paulo: Saraiva, 2011, pp. 395-436.

ROXIN, Claus. Derecho procesal penal. Trad. esp. Gabriela Córdoba e Daniel Pastor. Buenos Aires: Del Puerto, 2000. 
SAAD, Marta. O direito de defesa no inquérito policial. São Paulo: Revista dos Tribunais, 2004.

SALVADEGO, Laura. La normativa internazionale sulla protezione dei testimoni nel contrasto alla criminalità organizzata transnazionale. In: Rivista di Diritto Internazionale, $\mathrm{v}$. 98, n. 1, 1994, pp. 143-47.

SALZ, Rubin. Parker v. Randolph: Narrowing the scope of the confrontation clause in interlocking confessions cases. In: Brooklyn Law Review, v. 46, n. 2, 1980, pp. 345-72.

SANGUINÉ, Odone. Prisão cautelar, medidas alternativas e direitos fundamentais. Rio de Janeiro: Forense, 2014.

SANTALUCIA, Bernardo. Diritto e processo penale nell'antica Roma. 2. ed. Milano: Giuffrè, 1998.

SARLET, Ingo Wolfgang. A eficácia dos direitos fundamentais. 2. ed. Porto Alegre: Livraria do Advogado, 2001.

SCAPARONE, Metello. “Common law” e processo penale. Milano: Giuffrè, 1974.

SCHUON, Christine. International Criminal Procedure: A clash of legal cultures. The Hague: TMC Asser, 2010.

SEIÇA, António Alberto Medina de. O conhecimento probatório do co-arguido. Coimbra: Coimbra, 1999.

SEIGEL, Michael L.; e WEISMAN, Daniel. The admissibility of co-conspirator statements in a post-Crawford world. In: Florida State University Law Review, v. 34, n. 3, 2007, pp. $877-912$.

SERRANO, Nicolás González-Cuéllar. Proporcionalidad y derechos fundamentales en el proceso penal. Madrid: Colex, 1990.

SILVA, De Plácido e. Vocabulário jurídico. 6. ed., vv. 1, 2 e 4. Rio de Janeiro: Forense, 1980.

SILVA, Eduardo Araujo da. Organizações criminosas: Aspectos penais e processuais da Lei $n^{\circ}$ 12.850/13. São Paulo: Atlas, 2014.

SILVA, Fernando Muniz. A delação premiada no direito brasileiro. In: De Jure Revista Jurídica do Ministério Público do Estado de Minas Gerais, v. 10, n. 17, 2011, pp. 121-65.

SILVA, José Afonso da. Curso de direito constitucional positivo. 31. ed. São Paulo: Malheiros, 2008.

SILVA, Sandra Oliveira e. A protecção de testemunhas no processo penal. Coimbra: Coimbra, 2007.

SILVA, Virgílio Afonso da. A constitucionalização do direito: Os direitos fundamentais nas relações entre particulares. São Paulo: Malheiros, 2008.

Direitos fundamentais: Conteúdo essencial, restrições e eficácia. 2. ed., 3. reimp. São Paulo: Malheiros, 2014. 
. O proporcional e o razoável. In: Revista dos Tribunais, v. 798, 2002, pp. 23-50.

. Princípios e regras: Mitos e equívocos acerca de uma distinção. In: Revista LatinoAmericana de Estudos Constitucionais, v. 1, 2003, pp. 607-630.

SIQUEIRA, Geraldo Batista de. Confissão e tipo penal. In: NUCCI, Guilherme de Souza; e MOURA, Maria Thereza de Assis (Orgs.). Doutrinas essenciais: Processo penal. V. 3. São Paulo: Revista dos Tribunais, 2012, pp. 603-11.

SOUZA, Diego Fajardo Maranha Leão. O anonimato no processo penal: Proteção a testemunhas e o direito à prova. 1. ed. Belo Horizonte: Arraes, 2012.

SOUZA, João Fiorillo de. A retirada do réu da sala de audiência e o novo artigo 217 do CPP. In: Boletim IBCCRIM, v. 16, n. 192, 2008, p. 1.

SPENCER, J. R. Hearsay evidence in criminal proceedings. 2. ed. Oxford: Hart, 2014.

STAVROS, Stephanos. The guarantees for accused persons under Article 6 of the European Convention on Human Rights: An analysis of the application of the Convention and a comparison with other instruments. Dordrecht: Martinus Nijhoff, 1993.

STEINER, Sylvia. A Convenção Americana sobre Direitos Humanos e sua integração ao processo penal. São Paulo: Revista dos Tribunais, 2000.

STONE, Marcus. Instant Lie Detection?: Demeanour and Credibility in Criminal Trials. In: Criminal Law Review, v. 38, n. 11, 1991, pp. 821-30.

STRECK, Lenio Luiz. A filosofia traída pela dogmática jurídica: Uma crítica à noção de verdade e ao livre convencimento no processo penal. In: MALAN, Diogo; e MIRZA, Flávio (Coords.). Setenta anos do Código de Processo Penal brasileiro: Balanço e perspectivas de reforma. Rio de Janeiro: Lumen Juris, 2011, pp. 215-48.

O livre convencimento e sua incompatibilidade com o dever de accountability hermenêutica: O sistema acusatório e a proteção dos direitos fundamentais no processo penal. In: MALAN, Diogo; e PRADO, Geraldo (Coords.). Processo penal e direitos humanos. Rio de Janeiro : Lumen Juris, 2014, pp. 156-87.

STRONG, John W. McCormick on Evidence. 5. ed. St. Paul: West, 1999.

SULLIVAN, John E. Bourjaily v. United States: A new rule for admitting coconspirator hearsay statements under Federal Rule of Evidence 801(d)(2)(E). In: Wisconsin Law Review, v. 1988 , n. 4, 1988, pp. 577-604.

SUMMERS, Della (Dir.). Longman dictionary of contemporary English. 4. ed., 3. reimp. Harlow: Pearson, 2007.

SUMMERS, Sarah. Fair trials: The European criminal procedural tradition and the European Court of Human Rights. Oxford: Hart, 2007.

. The right to confrontation after Crawford v. Washington: A 'Continental European' perspective. In: International Commentary on Evidence, v. 2, n. 1, 2004, pp. 1-13.

SWIFT, Eleanor. Abolishing the hearsay rule. In: California Law Review, v. 75, n. 1, 1987, pp. 495-519. 
TALBOTT, Rebecca Sims. What remains of the "forfeited" right to confrontation?: Restoring Sixth Amendment values to the forfeiture-by-wrongdoing rule in light of Crawford v. Washington and Giles v. California. In: New York University Law Review, v. 85, n. 4, 2010, pp. 1291-1345.

TARUFFO, Michele. Il diritto alla prova nel processo civile. In: Rivista di Diritto Processuale, v. 39, n. 4 (supl.), 1984, pp. 74-120.

$\overline{2009 .}^{.}$La semplice verità: Il giudice e la costruzione dei fatti. 1. ed. Roma-Bari: Laterza,

THORNTON, Peter. The pejudiced defendant: Unfairness suffered by a defendant in a joint trial. In: Criminal Law Review, v. 50, n. 7, 2003, pp. 433-45.

TONINI, Paolo. A prova no processo penal italiano. Trad. port. Alexandra Martins e Daniela Mróz. São Paulo: Revista dos Tribunais, 2002.

. Il diritto a confrontarsi con l'accusatore. In: Diritto Penale e Processo, v. 2, n. 12, 1998, pp. 1506-12.

. Il diritto dell'imputato a interrogare colui che lo accusa e diritto di non rispondere. In: Diritto Penale e Processo, v. 1, n. 3, 1997, pp. 353-57.

Imputato "accusatore" ed "accusato" nei principali ordinamenti processuali dell'Unione Europea. In: Aa. Vv. Le nuove leggi penali: Abuso d'ufficio, dichiarazioni del coimputato, videoconferenze giudiziarie - Problemi attuali della giustizia penale. Padova: Cedam, 1998, pp. 261-72.

La prova penale. 4. ed. Padova: Cedam, 2000.

TORNAGHI, Hélio. Instituições de processo penal. 2. ed., v. 4. São Paulo: Saraiva, 1978.

TOURINHO FILHO, Fernando da Costa. Processo penal. 34. ed., vv. 1, 2 e 3. São Paulo: Saraiva, 2012.

TRINDADE, Antônio Augusto Cançado. A proteção internacional dos direitos humanos. São Paulo: Saraiva, 1991.

TUCCI, Rogério Lauria. Direitos e garantias individuais no processo penal brasileiro. 4. ed. São Paulo: Revista dos Tribunais, 2009.

. Habeas corpus, ação e processo. São Paulo: Saraiva: 1978.

. Lineamentos do processo penal romano. São Paulo: Bushatsky, 1976.

UBERTIS, Giulio. Il contraddittorio nella formazione della prova penale. In: YARSHELL, Flávio Luiz; e MORAES, Maurício Zanoide de (Orgs.). Estudos em homenagem à Professora Ada Pellegrini Grinover. São Paulo: DPJ, 2005, pp. 331-40.

. La prova penale: Profili giuridici ed epistemologici. Torino: UTET, 1995.

VANDERPUYE, Kweku. Traditions in conflict: The internalization of confrontation. In: Cornell International Law Journal, v. 43, n. 3, 2010, pp. 513-83. 
VASCONCELLOS, Vinicius Gomes de. Barganha e justiça criminal negocial: Análise das tendências de expansão dos espaços de consenso no processo penal brasileiro. São Paulo: IBCCRIM, 2015.

2017.

. Colaboração premiada no processo penal. 1. ed. São Paulo: Revista dos Tribunais,

VENTURINI, Carlo. Quaestiones non permanenti: Problemi di definizione e di tipologia. In: BURDESE, Alberto (Org.). Idee vecchie e nuove sul diritto criminale romano. Padova: Cedam, 1988, pp. 85-116.

VIERING, Marc. Right to a fair and public hearing. In: VAN DIJK, Pieter; et alia (Eds.). Theory and practice of the European Convention of Human Rights. 4. ed. Antwerpen: Intersentia, 2006, pp. 511-649.

VILARES, Fernanda Regina. A prova penal no direito inglês. In: FERNANDES, Antonio Scarance; ALMEIDA, José Raul Gavião de; e MORAES, Maurício Zanoide de (Coords.). Provas no processo penal: Estudo comparado. São Paulo: Saraiva, 2011, pp. 358-94.

WEISE, James H. Interlocking confessions in Courts-Martial. In: Army Lawyer, v. 1982, n. 8, 1982, pp. 11-19.

WELLMAN, Francis Lewis. The art of cross-examination. 4. ed. New York: Macmillan, 1948.

WELZEL, Hans. El nuevo sistema del derecho penal: Una introducción a la doctrina de la acción finalista. Trad. esp. José Cerezo Mir. Barcelona: Ariel, 1964.

WIDDER, Elmar. The right to challenge witnesses: An application of Strasbourg's flexible "sole and decisive" rule to other human rights. In: Cambridge Journal of International and Comparative Law, v. 3, n. 4, 2014, pp. 1084-97.

WIDDISON, Jason. Michigan v. Bryant: The ghost of Roberts and the return of reliability. In: Gonzaga Law Review, v. 47, n. 1, 2011, pp. 219-40.

WIGMORE, John Henry. A treatise on the Anglo-American system of evidence in trials at common law: Including the statutes and judicial decisions of all jurisdictions of the United States and Canada. 3. ed., v. 3. Boston: Little, Brown, and Co., 1940.

WILDE, Bas de. A fundamental review of the ECHR right to examine witnesses in criminal cases. In: International Journal of Evidence \& Proof, v. 17, n. 2, 2013, pp. 157-82.

WORRALL, John L.; HEMMENS, Craig; e NORED, Lisa S. Criminal Evidence: An introduction. 2. ed. Oxford: Oxford University, 2012.

YARSHELL, Flávio Luiz. Antecipação da prova sem o requisito da urgência e direito autônomo à prova. São Paulo: Malheiros, 2009.

. Investigação e autonomia do direito à prova: Um avanço necessário para a teoria geral do processo. In: ZUFELATO, Camilo; e YARSHELL, Flávio Luiz (Orgs.). 40 anos da teoria geral do processo no Brasil. São Paulo: Malheiros, 2013, pp. 326-33. 
YEE, Ellen Liang. Forfeiture of confrontation right in Giles: Justice Scalia's faint-hearted fidelity to the common law. In: The Journal of Criminal Law \& Criminology, v. 100, n. 4, 2010, pp. 1495-1548.

YOUNGER, Irving. Confrontation and hearsay: A look backward, a peek forward. In: Hofstra Law Review, v. 1, n. 1, 1973, pp. 32-42.

ZAFIS, Craig. Parkerv. Randolph: Redacting the Bruton rule. In: Criminal Justice Journal, v. 3, n. 2, 1980, pp. 521-36.

ZANDER, Michael. Zander on PACE. 6. ed. London: Sweet \& Maxwell, 2013.

ZAPPALÀ, Salvatore. Human rights in international criminal proceedings. Oxford: Oxford University, 2003. 


\section{LISTA DAS FONTES JURISPRUDENCIAIS}

Comitê de Direitos Humanos das Nações Unidas

Arutyuniantz v. Uzbekistan, UNHRC, Views: Communication No. 971/2001, CCPR/C/83/D/971/2001, 13/04/2005

Askarov v. Kyrgyzstan, UNHRC, Views: Communication No. 2231/2012, CCPR/C/116/D/2231/2012, 11/05/2016

Compass v. Jamaica, UNHRC, Views: Communication No. 375/1989, CCPR/C/49/D/375/1989, 03/11/1993

Dugin v. Russian Federation, UNHRC, Views: Communication No. 815/1998, CCPR/C/81/D/815/1998, 18/08/2004

Dunaev v. Tajikistan, UNHRC, Views: Communication No. 1195/2003, CCPR/C/95/D/1195/2003, 22/04/2009

Gapirjanova v. Uzbekistan, UNHRC, Views: Communication No. 1589/2007, CCPR/C/98/D/1589/2007, 11/05/2010

Guerra de la Espriella c. Colombia, UNHRC, Dictamen: Comunicación $N^{o}$ 1623/2007, CCPR/C/98/D/1623/2007, 11/05/2010

Idiev v. Tajikistan, UNHRC, Views: Communication No. 1276/2004, CCPR/C/95/D/1276/2004, 23/04/2009

Jessop v. New Zealand, UNHRC, Views: Communication No. 1758/2008, CCPR/C/101/D/1758/2008, 21/04/2011

Karimov and Nursatov v. Tajikistan, UNHRC, Views: Communications Nos. 1108/2002 and 1121/2002, CCPR/C/89/D/1108\&1121/2002, 03/05/2007

Khoroshenko v. Russian Federation, UNHRC, Views: Communication No. 1304/2004, CCPR/C/101/D/1304/2004, 29/04/2011

Koreba v. Belarus, UNHRC, Views: Communication No. 1390/2005, CCPR/C/100/D/1390/2005, 24/11/2010

Larrañaga v. Philippines, UNHRC, Views: Communication No. 1421/2005, CCPR/C/87/D/1421/2005, 14/09/2006

Maleki v. Italy, UNHRC, Views: Communication No. 699/1996, CCPR/C/66/D/699/1996, 13/09/1999

Peart and Peart v. Jamaica, UNHRC, Views: Communications Nos. 464/1991 \& 482/1991, CCPR/C/D/464/1991 \& 482/1991, 24/07/1995

Pustovoit v. Ukraine, UNHRC, Views: Communication No. 1405/2005, CCPR/C/110/D/1405/2005, 12/05/2014

Rodríguez Orejuela c. Colombia, UNHRC, Dictamen: Comunicación No 848/1999, CCPR/C/75/D/848/1999, 20/09/2002 
Rouse v. Philippines, UNHRC, Views: Communication No. 1089/2022, CCPR/C/84/D/1089/2002, 05/08/2005

Semey v. Spain, UNHRC, Views: Communication No. 986/2001, CCPR/C/78/D/986/2001, 19/09/2003

Toshev v. Tajikistan, UNHRC, Views: Communication No. 1499/2006, CCPR/C/101/D/1499/2006, 28/04/2011

Corte Interamericana de Direitos Humanos

"Panel Blanca" (Paniagua-Morales y otros) vs. Guatemala, IACtHR, Sentencia de fondo, 08/03/1998

Castillo Petruzzi et. al. v. Peru, IACtHR, Merits, reparations, and costs, 30/05/1999, Series C no. 52

García Prieto et al. v. El Salvador, IACtHR, Preliminary objections, merits, reparations and costs, 20/11/2007, Series C no. 168

García-Asto and Ramírez-Rojas, IACtHR, Preliminary objection, merits, reparations and costs, 25/11/2005, Series C no. 137

Lori Berenson-Mejía v. Peru, IACtHR, Merits, reparations and costs, 25/11/2004, Series C no. 119

Norín Catrimán et. al. v. Chile, IACtHR, Merits, reparations and costs, 29/05/2014, Series C no. 279

Palamara-Iribarne v. Chile, IACtHR, Merits, reparations, and costs, 22/11/2005, Series C no. 135

Ricardo Canese v. Paraguay, IACtHR, Merits, reparations and costs, 31/08/2004, Series C no. 111

Ruano Torres y otros vs. El Salvador, IACtHR, Fondo, reparaciones y costas, 05/10/2015, Series C no. 303

Zegarra Marín vs. Perú, IACtHR, Excepciones preliminares, fondo, reparaciones y costas, 15/02/2017, Series C no. 331

\section{Estados Unidos da América}

Barber v. Page, 390 U.S. 719 (1968)

Berger v. California, 393 U.S. 314 (1969) 
Bourjaily v. United States, 483 U.S. 171 (1987)

Bruton v. United States, 391 U.S. 123 (1968)

Bullcoming v. New Mexico, 564 U.S. 647 (2011)

California v. Green, 399 U.S. 149 (1970)

Chapman v. California, 386 U.S. 18 (1967)

Crawford v. Washigton, 541 U.S. 36 (2004)

Cruz v. New York, 481 U.S. 186 (1987)

Davis v. Washington, 547 U.S. 813 (2006)

Delli Paoli v. United States, 352 U.S. 232 (1957)

Douglas v. Alabama, 380 U.S. 415 (1965)

Dowdell v. United States, 221 U.S. 325 (1911)

Dutton v. Evans, 400 U.S. 74 (1970)

Gideon v. Wainwrigh, 372 U.S. 355 (1963)

Giles v. California, 554 U.S. 353 (2008)

Gray v. Maryland, 523 U.S. 185 (1998)

Griffin v. California, 380 U.S. 609 (1965)

Hammon v. Indiana, 546 U.S. 976 (2005)

Harrington v. California, 295 U.S. 250 (1969)

Idaho v. Wright, 497 U.S. 805 (1990)

Jackson v. Denno, 378 U.S. 368 (1964)

Kirby v. United States, 174 U.S. 47 (1899)

Lee v. Illinois, 476 U.S. 530 (1986)

Mattox v. United States, 146 U.S. 140 (1892)

Mattox v. United States, 156 U.S. 237 (1895)

Melendez-Diaz v. Massachusetts, 557 U.S. 305 (2009)

Michigan v. Bryant, 562 U.S. 344 (2011)

Mima Queen v. Hepburn, 11 U.S. (7 Cranch) 290 (1813)

Miranda v. Arizona, 384 U.S. 436 (1966)

Motes v. United States, 178 U.S. 458 (1900)

Nelson v. O’Neil, 402 U.S. 622 (1971)

Ohio v. Clark, 576 U.S. (2015)

Ohio v. Roberts, 448 U.S. 56 (1980)

Parker v. Randolph, 442 U.S. 62 (1979)

Pointer v. Texas, 380 U.S. 400 (1965)

Richardson v. Marsh, 481 U.S. 200 (1987) 
Roberts v. Russell, 392 U.S. 293 (1969)

Salinger v. United States, 272 U.S. 542 (1926)

Schneble v. Florida, 405 U.S. 427 (1972)

Tennessee v. Street, 471 U.S. 409 (1975)

United States v. Inadi, 475 U.S. 387 (1986)

White v. Illinois, 502 U.S. 346 (1992)

\section{$\underline{\text { Inglaterra e País de Gales }}$}

Lawrence v R [1933] AC 699

McPherson v McPherson [1936] AC 177

$R$ v Al-Khawaja [2006] 1 WLR 1078

$R v$ Alves [1997] 1 Cr App R 78

$R v$ Archer [2002] EWCA Crim 1996

$R v$ Archer [2007] EWCA Crim 930

$R v$ Barnes [1991] Crim LR 132

$R v$ Browne [1906] 70 JP 472

$R v$ Burrows [2000] Crim LR 48

$R v$ Campbell [2005] EWCA Crim 2078

$R v$ Cole [2008] EWCA Crim 3234

$R v$ Cordingley [2007] EWCA Crim 2174

$R v$ Dragic [1996] 2 Cr App R 232

$R v$ Governor of Pentonville Prison, ex p Osman [1989] 3 All ER 701

$R v$ Grant [1944] 1 All ER 311

$R v$ Gunewardene [1951] 35 Cr App R 80

$R v$ Horncastle [2009] EWCA Crim 964

$R v$ Horncastle [2009] UKSC 14

$R v$ Howson [1981] 74 Cr App R 172

$R v$ Hulusi [1973] 58 Cr App R 378

$R v$ Hussein [1998] Crim LR 820

$R$ v Ibrahim [2012] 4 All ER 225

$R$ v James Paul [1920] 2 KB 183

$R v$ Jones (Robert) (No 2) [1972] 1 WLR 887 
$R v$ Jones [2002] UKHL 5

$R v$ Jones, Planter and Pengelly [1991] Crim LR 856

$R v$ Kearley (Alan Robert) (No 1) [1992] 2 AC 228

$R v$ Knowlden [1991] 77 Cr App R 48

$R v$ Lake [1997] 64 Cr App R 172

$R v$ Makanjuola [1995] 1 WLR 1348

$R v$ McLean [2008] 1 Cr App R 11

$R v$ Moghal [1977] 65 Cr App R 56

$R$ v Myers [1996] 2 Cr App R 335

$R v$ Reynolds [1950] 1 All ER 335

$R v$ Rhodes [1960] 44 Cr App R 23

$R v$ Riat [2012] EWCA Crim 1509

$R v$ Richards [2007] EWCA Crim 709

$R v$ Rothwell [1994] 98 Cr App R 388

$R v$ Rudd [1948] 32 Cr App R 138

$R v$ Sellick [2005] 1 WLR 3257

$R v$ Sharp [1988] 1 WLR 7

$R v$ Sharrock [1948] 1 All ER 145

$R v$ Shaw (Elvis) [1980] 1 WLR 1526

$R v$ Stannard [1965] 2 QB 1

$R v$ Tahery [2006] EWCA Crim 529

$R v$ Taylor [2006] 2 Cr App R 14

$R v$ Weaver [1968] 1 QB 353

$R v Y$, [2008] 1 Cr App R 34

Scott \& Anor v Scott [1913] AC 417

$\underline{\text { República Federativa do Brasil }}$

STF, ADPF 347, Pleno, Rel. Marco Aurélio, DJe 19-02-16

STF, ARE 766977 AgR, $1^{\text {a }}$ Turma, Rel. Luiz Fux, DJe 07-11-13

STF, HC 100693, $1^{\text {a }}$ Turma, Rel. Luiz Fux, DJe 13-09-11

STF, HC 103205, $1^{\text {a }}$ Turma, Rel. Ricardo Lewandowski, DJe 10-09-10

STF, HC 109051, $1^{\text {a }}$ Turma, Rel. Roberto Barroso, DJe 20-10-14 
STF, HC 109390, $2^{\text {a }}$ Turma, Rel. Gilmar Mendes, DJe 08-10-12

STF, HC 115266, $2^{\text {a }}$ Turma, Rel. Gilmar Mendes, DJe 23-09-13

STF, HC 127483, Pleno, Rel. Dias Toffoli, DJe 04-02-16

STF, HC 73898, 2ª Turma, Rel. Maurício Corrêa, DJ 16-08-96

STF, Inq 3983, Pleno, Rel. Teori Zavascki, 12-05-16

STF, Inq 4119, $2^{\text {a }}$ Turma, Rel. Teori Zavascki, DJe 05-02-16

STF, Rcl 21258 AgR, 2 ${ }^{\text {a }}$ Turma, Rel. Dias Toffoli, DJe 20-04-16

STF, Rcl 24116, 2 ${ }^{\mathrm{a}}$ Turma, Rel. Gilmar Mendes, DJe 13-02-17

STF, RHC 111251 AgR, Pleno, Rel. Celso de Mello, DJe 29-10-14

STJ, AgRg no AREsp 693181, $5^{\text {a }}$ Turma, Rel. Ribeiro Dantas, DJe 15-03-17

STJ, AgRg no AREsp 890049, $5^{\text {a }}$ Turma, Rel. Reynaldo Soares da Fonseca, DJe 2811-16

STJ, AgRg no REsp 1505705, 6ª Turma, Rel. Sebastião Reis Júnior, DJe 21-11-16

STJ, AgRg no REsp 1669722, $6^{\text {a }}$ Turma, Rel. Maria Thereza de Assis Moura, DJe 3108-17

STJ, HC 383337, $5^{\text {a }}$ Turma, Rel. Jorge Mussi, DJe 22-03-17

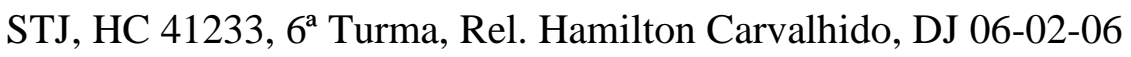

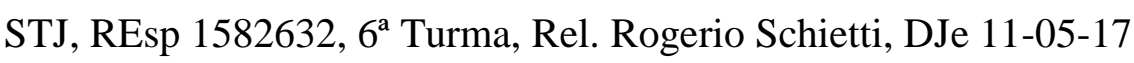

STJ, REsp. 1561021, 6 $6^{\mathrm{a}}$ Turma, Rel. p/ acórdão Nefi Cordeiro, DJe 25-04-16

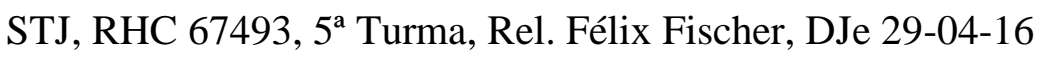

TJSC, Apl 20110762173, $3^{\text {a }}$ Câmara Criminal, Rel. Leopoldo Augusto Brüggemann, j. $16 / 07 / 13$

TJSP, Apl 0002321-82.2014.8.26.0142, 15ª Câmara Criminal, Rel. Julio Caio Farto Salles, DJe 19-12-17

\section{$\underline{\text { República Italiana }}$}

Cass. crim., sez. I, sent. 02/03/1996, n. 205280

Cass. crim., sez. I, sent. 21/12/1994, n. 1699

Cass. crim., sez. II, sent. 15/10/2008, n. 38894

Cass. crim., sez. II, sent. 22/11/2017, n. 53207

Cass. crim., sez. IV, sent. 03/09/1996, n. 205990

Cort. Cos., sent. 24/1992

Cort. Cos., sent. 254/1992 
Cort. Cos., sent. 361/1998

Cort. Cos., sent. 373/1992

Cort. Cos., sent. 440/2000

\section{$\underline{\text { República Portuguesa }}$}

TRE, processo 117/08.3GBRMZ.E1, Secção Criminal, Rel. Ana Barata de Brito, j. 1703-15

$\underline{\text { Tribunal Europeu de Direitos Humanos }}$

Adolf v. Austria, no. 8269/78, Commission Report 08/10/1988, Series B no. 43

Akkoç v. Turkey, nos. 22947/93 e 22948/93, ECHR 2000-X

Al-Khawaja and Tahery v. United Kigdom [GC], nos. 26766/05 e 22228/06, ECHR 2011

Al-Khawaja and Tahery v. United Kingdom, nos. 26766/05 e 22228/06, ECHR 2009

Artner v. Austria, 28/08/1992, Series A no. 242-A

Asch v. Austria, 26/04/1991, Series A no. 203

Barberà, Messegue and Jabardo v. Spain, 06/12/1988, Series A no. 146

Blokhin v. Russia, no. 47152/06, ECHR 2013

Bocos-Cuesta v. The Netherlands, no. 54789/00, ECHR 2005

Bricmont v. Belgium, 07/07/1989, Series A no. 158

Caka v. Albania, no. 44023/02, ECHR 2009

Cardot v. France, 19/03/1991, Series A no. 200

Damir Sibgatullin v. Russia, no. 1413/05, ECHR 2012

Delta v. France, 19/12/1990, Series A no. 191-A

Deweer v. Belgium, 27/02/1980, Series A no. 35

Dombo Beheer v. The Netherlands, 27/10/1993, Series A no. 274

Doorson v. The Netherlands, no. 20524/92, 26/03/1996, ECHR 1996-II

Ellis, Simms and Martin v. United Kingdom, nos. 46099/06 e 46699/06, ECHR 2012

Engel v. The Netherlands, 08/06/1976, Series A no. 22

Ferrantelli and Santangelo vs. Italy, 07/08/1996, Serie A no. 937

Gani v. Spain, no. 61800/08, ECHR 2013

Harutyunyan v. Armenia, no. 36549/03, ECHR 2007-III 
Horncastle and others v. United Kingdom, no. 4184/10, ECHR 2014

Hümmer v. Germany, no. 26171/07, ECHR 2012

Is grò v. Italy, 19/02/1991, Series A no. 194-A

Kostovski v. The Netherlands, 20/11/1989, Series A no. 274

Lucà v. Italy, no. 33354/96, ECHR 2001

Lučič v. Croatia, no. 5699/11, ECHR 2014

Melnikov v. Russia, no. 23610/03, ECHR 2010

Mitkus v. Latvia, no. 7259/03, ECHR 2012

Saïdi v. France, 20/09/1993, Series A no. 261-C

Saïdi v. France, 20/09/1993, Series A no. 261-C

Sarkizov and others $v$ Bulgaria, nos. 37981/06, 38022/06, 39122/06 e 44278/06, ECHR 2012

Schatschaschwili v. Germany [GC], no. 9154/10, ECHR 2015

Selmouni v. France, 25803/94, ECHR 1999-V

Seton v. United Kingdom, no. 55287/10, ECHR 2016

Solakov v. The Former Yugoslav Republic of Macedonia, no. 47023/99, ECHR 2001$\mathrm{X}$

Taxquet v. Belgium, no. 926/05, ECHR 2009

Trampevski v. The Former Yugoslav Republic of Macedonia, no. 4570/07, ECHR 2012

Unterpertinger v. Austria, 24/11/1986, Series A no. 110

Verdam v. The Netherlands (dec.), no. 35253/97, ECHR 1999

Vidal v. Belgium, 22/04/1999, Series A no. 235-B

Windisch v. Austria, 27/09/1990, Series A no. 186 
